\title{
ANÁLISE DOS IMPACTOS DAS DIFERENTES POLÍTICAS DE GESTÃO DOS ESTOQUES DE SUPRIMENTOS EM UMA EMPRESA DO SETOR DE BEBIDAS ATRAVÉS DE SIMULAÇÃO
}

\section{IMPACT ANALISYS OF DIFFERENTS INVENTORY POLICIES ON THE INBOUND SUPPLY OF A BEVERAGES COMPANY USING SIMULATION}

\author{
Thiago Gomes da Silva ${ }^{1}$, Fabiano Barboza ${ }^{2}$; Lino G. Marujo ${ }^{3}$ \\ ${ }^{1}$ DEPRO- CEFET/RJ - Rio de Janeiro - Brasil - gomes.thiago@ globo.com \\ ${ }^{2}$ DEPRO- CEFET/RJ - Rio de Janeiro - Brasil - fabianobarboza@ gmail.com \\ ${ }^{3}$ DEPRO- CEFET/RJ - Rio de Janeiro - Brasil - linomarujo@ @efet-rj.br
}

\begin{abstract}
Resumo
O objetivo deste trabalho é avaliar o impacto das escolhas das diferentes políticas de gestão dos estoques de matéria-prima utilizando como ferramentas de simulação o Microsoft Excel em conjunto como @Risk. Como embasamento teórico foi realizado uma análise do valor dos estoques na cadeia de suprimentos, apresentada as principais decisões a serem tomadas na formulação de uma política de estoque, descrita a função da logística de suprimentos e seus impactos nos sistemas produtivos e, por fim, abordados aspectos relacionados à simulação e, mais especificamente, à ferramenta @ Risk. A empresa analisada é uma engarrafadora e distribuidora de bebidas que enfrenta alguns problemas com a gestão dos seus estoques de matéria primas e fatos subseqüentes que ocorrem. Através das simulações foram quantificados por meio de indicadores de desempenho os diversos efeitos das políticas propostas e analisados os seus impactos em custo e serviço para as matérias-primas em estudo, de modo a possibilitar a escolha de uma política que proponha um menor custo total respeitando os níveis de serviço desejados.
\end{abstract}

Palavras-chave: simulação, política de estoques, engarrafadora de bebidas.

\section{Introdução}

\subsection{Motivações do Estudo}

De modo geral, os estoques numa cadeia de suprimentos podem estar fisicamente nos fornecedores (como insumo), no elo responsável pela fabricação (na forma de insumos, produtos em processamento ou mesmo produtos acabados) e pode estar adiantado na cadeia em Centros de Distribuição (como produto acabado ou ainda em estado intermediário, caracterizando o "postponement", por exemplo). 
Wanke (2003, p. 11) ressalta que "é crescente a importância atribuída à gestão de estoques como elemento fundamental para a redução e o controle dos custos totais e melhoria do nível de serviço prestado pelas empresas".

Essa importância, como ressalta Correa et al (2001), fez com que empresas nos anos 80 baixassem seus estoques a todo custo, sem se preocupar com os possíveis impactos dessa atitude. Isso provavelmente reduziu custos, mas deve ter impactado negativamente os níveis de serviços das empresas.

Na década de 90, especialmente no Brasil, as altas taxas de juros praticadas pelo governo fizeram com que mais importância fosse dada aos estoques, já que o custo de oportunidade em manter estoques fica extremamente elevado.

Encontrar um ponto ótimo entre custo dos estoques e o nível de serviço segundo Ferreira Filho et al. (2005) é uma tarefa árdua dados o aumento da competição e proliferação do número de SKUs.

Essa proliferação de SKUs pode ser observada, por exemplo, nas indústrias de bebidas que hoje estão comercializando dezenas de novas linhas como os produtos light, diet, lemon além dos incontáveis novos tipos de embalagens, tornando extremamente difícil e trabalhosa a gestão de modo eficiente desses estoques, tanto de produtos acabados quanto matérias primas.

Motivado por todos os pontos acima a proposta deste projeto é avaliar o trade-off entre custos relacionados aos estoques e nível de serviço fazendo simulações com alguns modelos de estoques de modo a identificar como se comportam os indicadores em relação a essas políticas e com algumas sensibilidades propostas, dentro da indústria de bebidas selecionada. Todas essas análises estão sedimentadas nos conceitos que serão explanados nos próximos capítulos, cujas estruturas estão descritas a seguir.

\section{Estoques na cadeia de suprimentos}

Estoques existem para sincronizar oferta e demanda, visto que quase nunca podemos prever a demanda futura com exatidão e dificilmente temos os suprimentos disponíveis no instante que queremos. Sendo assim, com a formação de estoques podemos aumentar a disponibilidade do produto e a eficiência da produção e distribuição. Ballou (1993) apresenta algumas razões pelas quais devemos manter estoques. São elas:

- Melhorar o nível de serviço oferecido - estoques auxiliam o marketing pelo fato de disponibilizar o produto próximo ao centro de consumo, garantindo desta forma uma 
vantagem competitiva em produtos cujo nível de serviço tem peso considerável na hora de fechar uma venda;

- Incentivar a produção - estoques são amortecedores que equilibram oferta e demanda, permitindo uma produção mais constante, que não flutua de acordo com as vendas;

- Permitir economias de escala nas compras e no transporte - estoques possibilitam que seja comprada uma quantidade de material maior que a necessária para ganharmos tanto nos descontos por quantidade comprada quanto na utilização mais eficiente do transporte que fará a movimentação do material;

- Proteção contra alteração nos preços - antecipação de compras toda vez que for previsto um aumento de preço;

- Proteções contra oscilações na demanda ou no tempo de ressuprimento - estoques de segurança adicional ao estoque regular para atender a necessidade de produção ou de mercado;

- Proteção contra contingência - estoques para manter as operações normais quando acontece alguma emergência.

Bowersox e Closs (2001) consideram ainda mais dois fatores:

- Especialização geográfica - estoque permite que produtos sejam fabricados próximos aos locais onde as matérias-primas e os conhecimentos necessários para sua manufatura estão disponíveis para que depois sejam oferecidos no local de consumo. Conceito este que se confunde com a melhora do nível de serviço apresentada por Ballou.

- Aumenta a eficiência operacional - permite que cada produto seja fabricado e distribuído em lotes maiores que a demanda de mercado.

\subsection{Custos envolvidos na gestão de estoques}

Embora os estoques exerçam o importante papel de proteger as empresas contra as incertezas na demanda e no ressuprimento eles também trazem com eles elevados custos para organização. Desta maneira, na atividade de projeto ou gerenciamento de estoques é necessário verificar se o benefício gerado pelo estoque está sendo maior que mal (perda de dinheiro) causado por ele. Para nos ajudar nessas análises Ballou (1993) e Bowersox e Closs (2001) apresentam os custos que devem ser balanceados para tomarmos a decisão de mantermos ou não certa quantidade de produtos estocados. 


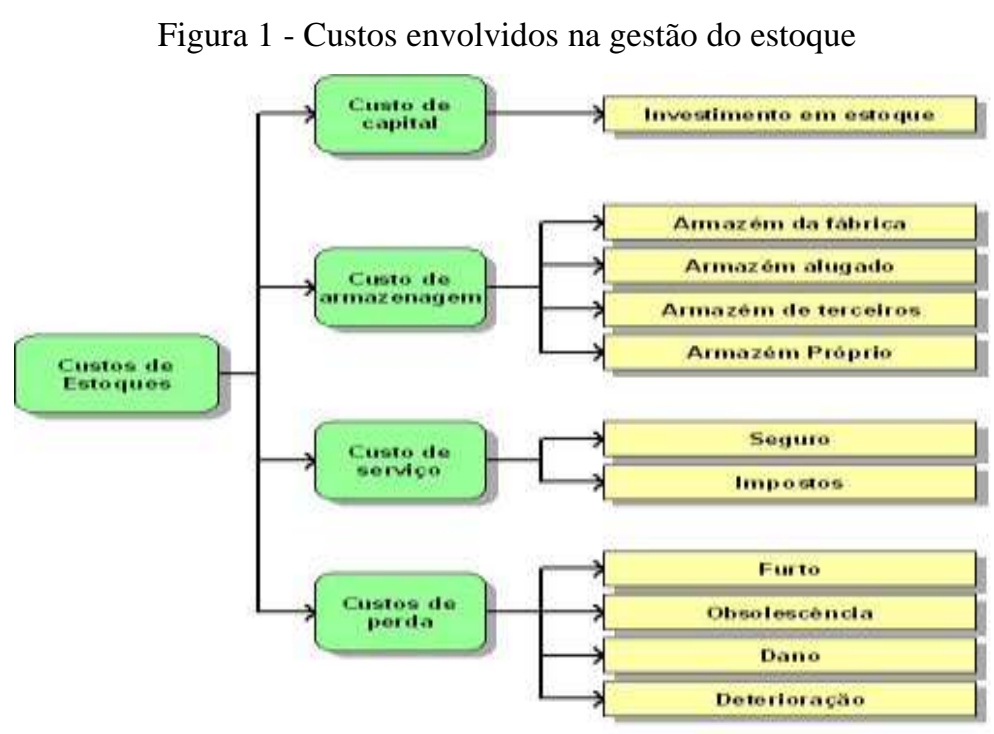

Fonte: Adaptado de Ferreira Filho et al. (2005)

A primeira categoria de custo abordada é o custo de manutenção de estoques. Esta é relativa à quantidade e ao tempo que produtos permanecem estocados. Um dos mais importantes custos desta categoria é o custo de oportunidade de capital, que é o dinheiro ganho se o capital imobilizado em estoque estivesse sendo investido em outros negócios. Este custo tem aumentado a preocupação com os níveis de estoques devido a altas taxas de juros praticadas pelo mercado nos últimos anos, especialmente no Brasil onde o governo usa os juros para conter a demanda e, desta forma, controlar a inflação.

Lima (2003) apresenta algumas diretrizes para cálculo do custo de oportunidade de capital. Ele diz que o custo de oportunidade de capital em uma empresa que apenas comercializa produtos, onde o valor do produto em estoque é seu preço de compra, pode ser calculado multiplicando o valor de compra dos produtos pela taxa de oportunidade de capital escolhida ou calculada pela organização, sendo taxa de oportunidade o valor percentual pelo qual o capital seria remunerado.

Nas organizações industriais o produto em estoque tem seu valor estimado com base no custo de produto vendido (CPV), que engloba tanto custos fixos quanto os variáveis, impedindo que o cálculo seja feito diretamente, como nas organizações que apenas comercializam produtos. Nas indústrias, para base de cálculo do custo de oportunidade de capital consideram-se apenas os custos variáveis, pois os custos fixos serão imobilizados independentemente dos produtos serem fabricados.

Nem sempre o custo de oportunidade de capital é facilmente determinado, pois muitas vezes existe dificuldade em se estimar a taxa de oportunidade de capital das organizações. Existem ainda outros fatores a serem considerados no momento de quantificação deste custo. A primeira consideração diz respeito à inclusão da parcela variável do custo de transporte ao custo do produto. 
E a segunda é que não se deve incluir o valor de produtos danificados, pois de nada vale o valor deste ativo que não pode ser comercializado.

Outros custos estão classificados aqui. São os custos com seguros contra incêndio, roubo e outros, custos de armazenagem, onde estão incluídos os custos com aluguel dos depósitos ou área de armazenagem e, por fim, os custos de perda por deterioração, furtos, obsolescência e dano.

A próxima categoria de custos envolvida na gestão dos estoques seriam os custos da falta. Ballou (1993) divide os custos de falta em dois grupos: custo de vendas perdidas e custo de atraso. Os custos de atraso são reprocessamento de pedidos, gastos extraordinários com transporte e manuseio. Ballou (1993) afirma ainda que somente produtos considerados bastante diferenciados podem sofrer atrasos sem causar desconforto aos clientes.

O custo de venda perdida é dinheiro perdido pelo não fechamento da venda ou qualquer evento futuro devido à imagem negativa que a falta ocasionou. Vendas perdidas prejudicam uma importante função logística, a disponibilidade. Desconsiderando os custos causados pela imagem negativa quando um cliente não encontra um produto desejado para compra, pode-se dizer que o custo da perda é a soma da margem de contribuição unitária (MCU) de cada produto não vendido. A MCU é definida como a diferença entre o preço de venda e a parcela variável dos custos de um produto, ou seja, representa o dinheiro se que deixou de ganhar pela não-venda do produto. É diferente do lucro unitário, pois seu cálculo não subtrai os custos fixos. Os custos relativos ao dano da imagem são de difícil mensuração (envolve, por exemplo, a perda de fidelidade do cliente) e por isso foram desconsiderados.

A última categoria são os custos relacionados a uma ordem de ressuprimento. Estariam inclusos nesta categoria os custos de processar pedido no departamento de compras, de enviar o pedido até o fornecedor, de set-up ou de manuseio para atender o lote solicitado, custo de qualquer tipo de manuseio ou processamento na doca de recepção e o preço da mercadoria.

\subsection{Relação entre custo do excesso e o custo da falta de estoques}

A relação entre os custos do excesso e o custo da falta de um produto em estoque tem uma importância significativa na hora de determinar a política de estoque de uma organização e no relacionamento entre elos da cadeia de suprimentos. Lima (2003) afirma que "o trade-off entre o custo do excesso e o custo da falta é chave para parametrização de qualquer modelo de gestão de estoque, independente do método adotado" e logo depois faz algumas abordagens que serão vistas a seguir.

O custo de excesso corresponde ao custo da permanência de um produto não vendido no estoque, logo está relacionado com o custo de manutenção de um item no estoque. Já o custo da falta é aquele relacionado com a perda de receita devido à falta de um item no estoque quando 
solicitado pelo cliente. Baseado nestes conceitos é correto afirmar que quanto maior o custo de excesso, menor será o estoque de segurança e quanto maior o custo da falta maior será a tendência de se proteger contras as incertezas utilizando estoques.

Visto que os custos de manutenção de estoques são proporcionais ao custo variável e definem o custo do excesso, concluí-se que empresas com percentual de custos fixos bem maiores que os custos variáveis tendem a volumes maiores de inventário, pois possuem um baixo custo de excesso de estoques. Em contra partida empresas onde o custo variável ocupa uma parcela bem maior que os custos fixos se preocupam mais em baixar seus níveis de estoques, pois o custo de excesso torna-se muito alto e sua baixa MCU (diferença entre receita custos variáveis) indica baixo custo de falta.

\subsection{Estoques e seu impacto na gestão de finanças}

O nível de estoque é refletido em importantes indicadores financeiros estratégicos, mostrando o quanto as quantidades de estoques desnecessárias impactam negativamente no processo de criação de valor para uma empresa e na elevação de seu valor de mercado. Estas duas atividades, tradicionalmente, "significam aumentar a lucratividade ou rentabilidade empresarial, dada pela relação entre o lucro líquido e o ativo total” (Moori et al, 2000, p. 109).

Figura 2 - Ilustração do impacto dos estoques nas finanças das empresas

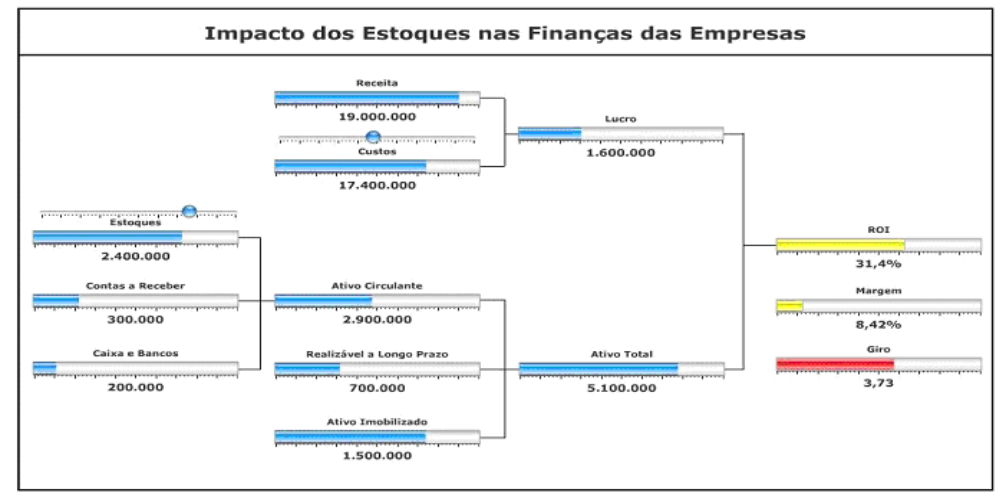

Fonte: Fiúza (2006)

Num ambiente cada vez mais competitivo as empresas são forçadas a gerar mais lucro com menos investimentos para se manterem no mercado. Numa linguagem contábil, isto significa aumentar o lucro e reduzir os ativos. Dentro desta visão Lima (2003) coloca a diminuição dos estoques como a maneira mais rápida e muitas vezes mais fácil de minimizar os ativos para aumentar o retorno sobre o investimento (ROI) ou, como também é conhecido, retorno sobre os ativos (RSA). O ROI é definido como a razão entre o lucro líquido e os ativos da empresa e como 
os estoques são ativos circulantes, na medida em que os níveis de estoques diminuem o ROI aumenta. A Figura 4 mostra relação entre o ROI e os estoques.

Lima (2003) apresenta um modelo estratégico de lucro que "é geralmente utilizado para gerar cenários e testar análises de sensibilidade do impacto da variação das contas do ativo, como o estoque, nos indicadores de retorno, os quais se tornaram os mais importantes mensuradores de performance das grandes empresas”. O modelo é usado para cálculo do retorno sobre patrimônio líquido (RSPL), que é o produto do ROI pela alavancagem financeira. A Figura 5 ilustra o modelo numa empresa fictícia e a Figura 3 mostra o impacto no RSPL (aumento de 20 para 22,2\%) desta empresa caso o estoque fosse reduzido de $25 \%$.

Figura 3 - Modelo Estratégico do Lucro

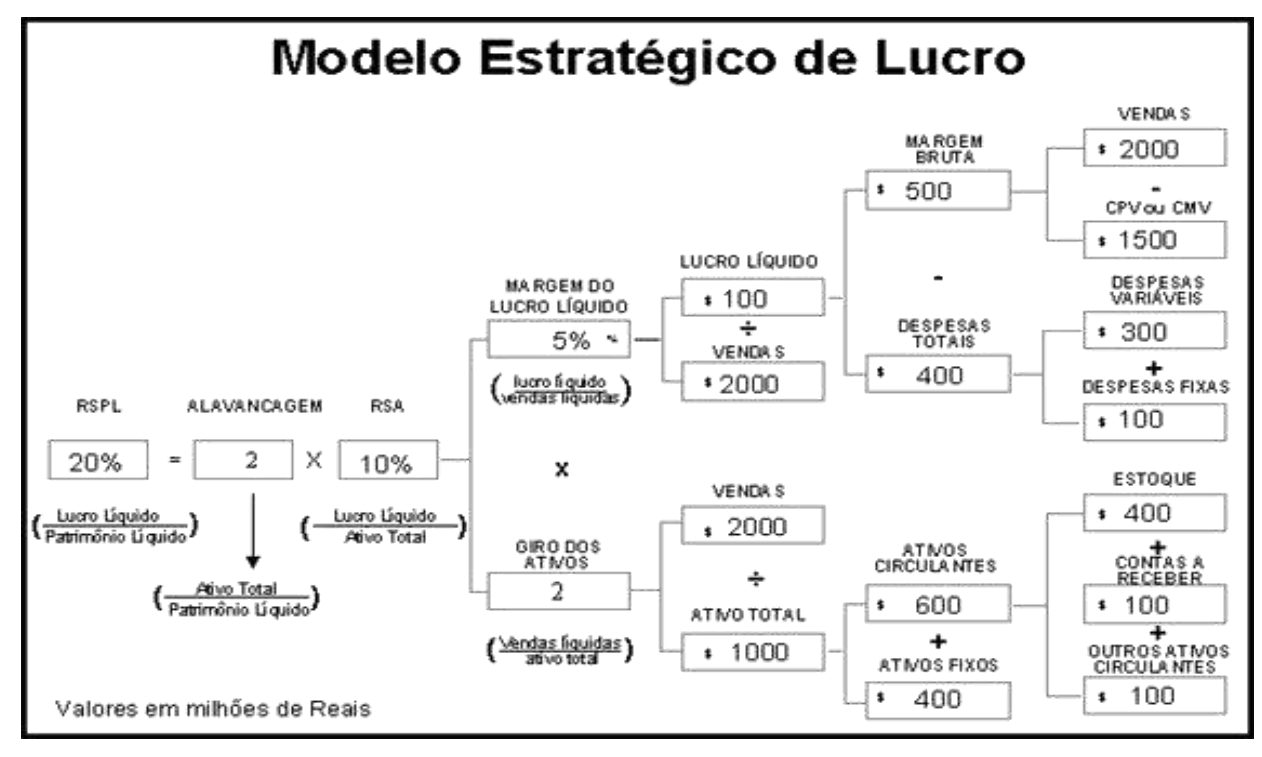

Fonte : Lima (2003)

Um outro indicador financeiro cujo estoque tem influência é o EVA (valor econômico agregado), que é definido como a diferença entre o lucro líquido e o custo de capital, sendo este último dividido entre custo capital de terceiros e custo de capital próprio. Sendo o estoque uma aplicação do capital da empresa, verifica-se que quanto maior for o nível de estoque, menor será o EVA. Uma medida de EVA negativa demonstra que o valor das ações da empresa está sendo destruído (Moori et al, 2000).

A Figura 4 nos mostra onde os estoques estão localizados na cadeia de suprimento e como os custos dos produtos são transferidos através dos elos. Através da figura percebe-se, por exemplo, que na medida em que nos afastamos do início da cadeia os custos variáveis vão tomando uma proporção cada vez maior em relação à estrutura de custos das empresas. Isto acontece porque os custos fixos de um elo são transferidos como custos variáveis para o elo seguinte. Desta forma 
também concluímos que quanto mais próximo do consumidor maior será a oportunidade de redução dos custos quando reduzimos os níveis de estoques.

Figura 4 - Transferência dos Custos de Estoque na Cadeia de Suprimentos

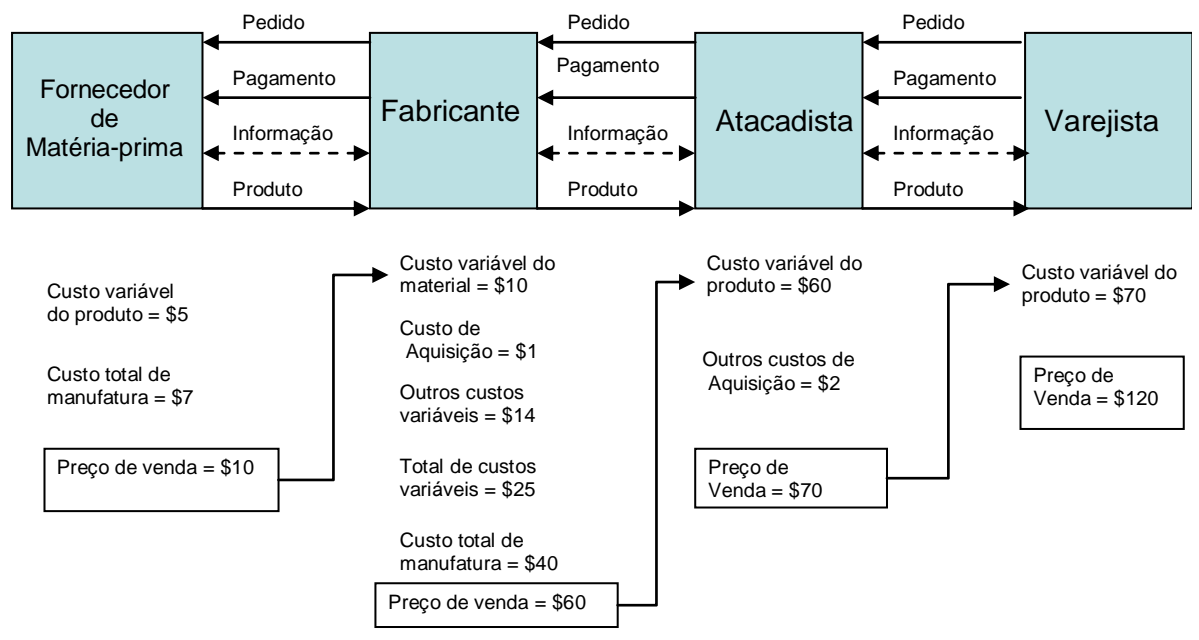

Fonte: Lambert e Pohlen (2001)

\subsection{Aspectos econômicos relacionados aos aspectos tecnológicos}

Wanke (2003) faz uma abordagem diferenciada dos aspectos econômicos da cadeia de suprimentos relacionando estes aos aspectos tecnológicos e suas implicações gerenciais. As quatro situações analisadas são: estrutura dos custos fixos e variáveis das operações que compõem cada empresa, o tempo de resposta das operações que compõem cada empresa, os custos adicionados acumulado ao final de cada empresa, a margem de contribuição obtida por cada empresa da cadeia ao negociar com a empresa da cadeia seguinte.

\subsection{Estrutura dos custos fixos e variáveis das operações que compõem cada empresa e o tempo de resposta destas.}

A estrutura de custos de uma organização determina sua flexibilidade em relação à velocidade, variedade e volume. Empresas que têm a maior parte dos seus custos representada pelos custos fixos são menos flexíveis a estes fatores, normalmente são empresas mais próximas das operações de extração dos recursos naturais. Ao contrário, empresas com uma faixa maior de custos variáveis possuem tempos de respostas (tempo para responder a colocação de um pedido) menores e menores limitações tecnológicas em relação às mudanças de volume e variedade, são empresas mais próximas ao consumidor final do produto.

Uma grande proporção de custos fixos induz as empresas a maiores lotes de produção, compra e distribuição devido aos longos tempos de resposta, pequena flexibilidade de volume e variedade e a possibilidade da diluição dos custos numa base maior de rateio. 


\subsection{Os custos adicionados acumulados ao final de cada empresa}

Custos adicionados são os custos acumulados da terra, ou seja, o início da cadeia de suprimentos, ao consumidor final. Quanto mais próximo ao consumidor, maiores serão os custos acumulados e, conseqüentemente, maior será o custo de oportunidade de capital na manutenção estoques, devido ao fato dos produtos terem maior valor agregado. Esta situação gera uma necessidade maior de capital de giro na empresa.

Menores custos adicionados e uma grande proporção de custos fixos leva a necessidade de gerar economias de escala na produção e distribuição. Enquanto altos custos adicionados somados a baixa parcela de custos fixos promovem a busca pela flexibilidade de volume e variedade.

\subsection{A margem de contribuição obtida por cada empresa da cadeia ao negociar com a empresa seguinte}

Aqui Wanke (2003) apresenta os principais fatores que influenciam as margens de contribuição: intensidade da concorrência, poder de barganha dos clientes e fornecedores, e grau de diferenciação dos produtos. Altas margens de contribuição levam as empresas a manterem maiores níveis de estoques, pois a falta de um produto pode ter um custo alto.

Dados os aspectos acima, verifica-se a complexidade dos relacionamentos na cadeia de suprimento. Ballou (1993) diz que um canal deve ser gerenciado pelas mesmas razões que as operações logísticas internas de uma firma, isto é, balancear custos de comportamento conflitantes, pois melhorias para um membro do canal podem significar aumento de custo para outro e isto pode levar a contramedida pelos elementos colocados em desvantagem. Isto reforça nossa idéia exposta no inicio deste tópico de que o entendimento dos aspectos econômicos facilita o relacionamento com os demais membros da cadeia de suprimentos.

\section{Políticas de Gerenciamento de estoques}

Na seção anterior foi observada a importância dos estoques tanto para cadeia de suprimentos como um todo quanto para uma empresa isoladamente. Embora não tenha sido diretamente citado, nota-se o relacionamento dos estoques com várias áreas tradicionais das organizações, como Produção e Marketing. Por exemplo, gerentes de produção tenderiam a fabricar grandes lotes para obterem ganhos de escalas e, consequentemente, aumentariam seu estoque médio de produtos acabados. No caso de Marketing essa relação é ainda mais evidente, visto que os estoques afetam diretamente uma das funções do Marketing, a disponibilidade. Poderíamos somar a estes exemplos o impacto na gerência de finanças, pois como já foi dito estoques imobilizam parte do capital da empresa e isto faria com que esta área pressionasse a redução dos níveis de estoques. 
Diante de tantas situações, muitas vezes com comportamento conflitantes, as empresas precisam pensar na melhor maneira de gerir seus estoques e estabelecer políticas que direcionem suas decisões. Gaither e Frazier (2004, p. 269) afirmam que "as políticas de estoques são suficientemente importantes para que gerentes de produção, marketing e finanças trabalhem juntos com a finalidade de alcançar um acordo sobre essas políticas, pois o fato de haver pontos de vistas conflitantes ressalta o equilíbrio que deve ser buscado entre metas também conflitantes".

\subsection{Principais conceitos relacionados aos estoques}

Antes de iniciar a discussão de política de estoque propriamente dita será apresentada à definição de alguns conceitos relacionados ao tema para um melhor entendimento do texto aqui exposto.

- Estoque a mão: é quantidade do item que está fisicamente na empresa. Determina se o cliente pode ser atendido no momento do pedido.

- Estoque líquido: é a diferença entre o estoque a mão e as encomendas.

- Estoque em trânsito: são os pedidos já realizados aos fornecedores, mas que ainda não chegaram à empresa.

- Estoque contábil: é a soma do estoque líquido com o estoque em trânsito.

- Estoque de segurança: O estoque de segurança é definido por Bowersox e Closs (2001) como o estoque usado no fim do ciclo de ressuprimento, quando incertezas geram aumento na demanda esperada ou nos tempos de ressuprimento mais longos, ou seja, é usado como proteção contra variações na demanda e no lead-time.

- Giro de estoque: indicador que mostra a rotação dos produtos no estoque. É calculado dividindo-se a demanda pelo nível médio dos estoques.

- Cobertura do estoque: indicador do período em que determinada quantidade em estoque atende a demanda. É calculado dividindo-se a quantidade em estoque pela demanda, ou seja, o inverso do giro de estoque.

\subsection{Definindo uma política de estoque}

Bowersox e Closs (2001, p.228) definem política de estoque como "normas sobre o que comprar ou produzir, quando acionar e em quais quantidades, podendo incluir também decisões de posicionamento e alocação de estoques em fábricas e centro de distribuição". Resumindo isto seria responder às quatros perguntas proposta por Wanke (2000): Onde localizar os estoques na cadeia de suprimentos? Quando pedir o ressuprimento? Quanto manter em estoques de segurança? Quanto pedir? 


\subsubsection{Localização}

Decisões sobre localização dos estoques na cadeia vão indicar o quão centralizado serão os nossos estoques. O nível de centralização dos estoques pode variar de um único armazém ou centro de distribuição (alto grau de centralização) até vários armazéns mais próximos dos clientes (baixo grau de centralização). Segundo Wanke (2000) a centralização vai depender do giro de estoque, lead-time de resposta (tempo de atendimento de um pedido realizado), nível de disponibilidade exigida pelo mercado e valor agregado.

Alto giro de estoque, lead time de resposta e nível de disponibilidade exigida nos levará a adotar política de estoques descentralizados. Produtos com alto giro nos induzem a descentralizar porque os riscos de obsolescência e o custo de oportunidade de capital é menor devido ao curto período em que eles ficam no armazém. Ao mantermos estoques próximo aos consumidores com a descentralização também reduzimos o tempo de resposta e aumentamos a disponibilidade para os clientes. Contrariando os três aspectos anteriores temos o valor agregado. Este quanto maior, mais centralizados serão os estoques, pois a descentralização aumenta os níveis de estoque de segurança que, somado ao alto preço dos produtos, elevam bastante o custo de oportunidade de capital.

\subsubsection{Quando emitir uma ordem de ressuprimento?}

O momento de emissão de uma ordem de ressuprimento vai depender do tipo de sistema adotado para controle de estoque. Existem dois tipos de tipos de sistemas: sistema de revisão contínua ou sistema de revisão periódica.

No sistema de revisão contínua os pedidos dos ressuprimentos de estoques para um determinado produto ou material podem ser realizado em qualquer instante, visto que os estoques são constantemente monitorados e sabemos seu nível a qualquer momento. Em síntese o que acontece é o seguinte: o armazém recebe um item para armazenar, elevando o nível de estoque desse item. Na medida em que o tempo passa, este item é consumido até que o nível de estoque chegue a um valor, chamado ponto de pedido, em que é emitida uma nova ordem de ressuprimento. Já no Sistema de Revisão Periódica as ordens são emitidas em intervalos pré-determidados de tempo. Por exemplo, no dia 30 de todo mês o nível de estoque é verificado e então se pede uma determinada quantidade para recompor o estoque.

Em geral sistemas de revisão contínua nos permitem operar com níveis menores de estoque de segurança, porém em muitos casos os sistemas de intervalo padrão são mais vantajosos por que nos permite emitir ordens de vários produtos ao mesmo tempo, proporcionando economia de escala sobre os custos fixos de emissão de pedido e permitindo consolidação de cargas. Sistemas de revisão periódica também se tornam úteis em ambientes poucos informatizados, pois os custos de controle de estoque são menores. 


\subsubsection{Determinando o ponto de pedido (PP) nos sistemas de revisão periódica}

O ponto de pedido é o nível de estoque necessário para suprir a demanda durante o tempo de ressuprimento (lead-time de compra). Em condições de certeza absoluta esse valor seria facilmente calculado, pois a demanda o e lead-time seriam conhecido. Por exemplo, suponha-se que tem uma demanda de três unidades por dias e seu lead-time de compras seja de dois dias. O ponto de pedido seria o produto da demanda diária pelo seu lead-time de compras, neste caso igual a seis unidades.

A condição de certeza citada no parágrafo anterior dificilmente acontece na prática. No mundo real existem incertezas, tanto na demanda quanto no lead-time de compras, que forçam o uso de um estoque de segurança para garantir a disponibilidade do item no período de ressuprimento. Desta forma o ponto de pedido é calculado como a soma do estoque necessário para cobrir o lead-time de compras com o estoque de segurança:

$$
\begin{aligned}
& \mathrm{PP}=\mathrm{DE} * \mathrm{LD}+\mathrm{ES}, \text { onde: } \mathrm{PP}=\text { ponto de pedido } \\
& \qquad \begin{array}{l}
\mathrm{LD}=\text { lead time de ressuprimento } \\
\mathrm{ES}=\text { estoque de segurança } \\
\mathrm{DE}=\text { demanda }
\end{array}
\end{aligned}
$$

\subsubsection{Estoque de Segurança}

Com a adoção do estoque de segurança mais uma questão precisa ser respondida para se formalizar uma política de estoque: Qual o tamanho do meu estoque de segurança? A importância desse questionamento se deve a conceitos já discutidos no primeiro capítulo, onde foi visto que estoque em excesso aumenta o custo de manutenção e pouco estoque aumenta o custo da falta.

Devido à dificuldade de se balancear com precisão o custo da falta e o custo do excesso Gaither e Frazier (2004) sugerem que o estoque de segurança seja calculado com base no conceito de nível de serviço, que se refere à probabilidade de que a falta de um produto em estoque não ocorra. Por exemplo, se um nível de serviço de $75 \%$ é estabelecido, isto significa dizer que existe $25 \%$ de chance da demanda durante o lead time de compras não ser totalmente atendida. Assim o ponto de pedido seria calculado com base numa análise estatística da demanda real durante os ressuprimentos no passado. Supondo que a distribuição de probabilidade de demanda durante o lead-time de compras seja uma normal o ponto de pedido seria calculado da seguinte maneira:

$$
\begin{aligned}
& \mathbf{P P}=\boldsymbol{\mu}+\text { z. } \boldsymbol{\sigma} \text {, onde: } \quad \boldsymbol{\mu}=\text { média da distribuiç̧ão. } \\
& \sigma=\text { desvio padrão da distribuição. }
\end{aligned}
$$




$$
\mathrm{z}=\text { coeficiente necessário para se alcançar o nível de serviço }
$$

desejado.

Entretanto Wanke (2000) alerta que mercados altamente competitivos obrigam as empresas a terem altos níveis de estoque de segurança, devido à exigência de disponibilidade dos produtos e a maior possibilidade de erros na previsão de demanda, e que nestes casos torna-se importante termos uma estimativa dos custos da falta para podermos fazer uma análise do risco de mantermos estoques. A análise preliminar proposta pode ser feita com a seguinte fórmula:

Risco $=1-\boldsymbol{c f} /(\boldsymbol{c} f+\boldsymbol{c e})$,

Onde $\boldsymbol{c} \boldsymbol{f}$ corresponde ao custo da falta e $\boldsymbol{c} \boldsymbol{e}$ o custo do excesso.

Sendo assim produtos com alto risco (alto valor agregado, alto risco de obsolescência, baixa margem de contribuição, etc) deveriam ter seus estoques subdimensionados e na outra ponta, produtos com alto custo de falta devem ter uma abordagem conservadora em relação aos seus estoques de segurança.

\subsubsection{Quanto pedir?}

Foi visto que nos sistemas de revisão contínua a ordem de compra é emitida no momento em que o estoque alcança o nível de pedido e nos sistema de revisão periódica a emissão ocorre em intervalos pré-definidos de tempo. No entanto no instante da emissão da ordem surge uma pergunta: qual quantidade pedir? Assim como o momento da emissão da ordem, a quantidade a ser pedida também está diretamente relacionada com o tipo de sistema escolhido para controlar estoques. Será visto agora os principais métodos (que são variações destes sistemas) que combinam o momento de pedir com a quantidade da ordem a ser emitida.

\subsection{Método de revisão contínua, ponto de pedido e lote econômico de compra (LEC)}

Neste modelo os estoques têm seus níveis controlados constantemente e seu ponto de pedido é calculado da maneira apresentada no item 3.2.3, é importante salientar que o ponto de pedido é obtido através do estoque contábil. A quantidade a ser pedida é calculada de acordo com um dos modelos mais antigos para controlar estoques, o lote econômico de compra (LEC).

Considere uma demanda $D$ no período de um 1 ano e um lote de compra com quantidade $Q$. Na medida em que a quantidade $Q$ é aumentada o custo de emissão de pedidos é reduzido, visto que será feito menos pedidos para atender a demanda $D$. No entanto os custos de manutenção de estoque se elevarão porque os níveis de estoques ficam mais altos. Da mesma forma, se a 
quantidade $Q$ for diminuída, o custo de emissão de pedido aumenta e o custo de manter estoques também diminui. O modelo do LEC calcula uma quantidade ótima que deve ser pedida considerando os comportamentos conflitantes dos custos de manutenção de estoque e emissão de pedidos. Bowersox e Closs (2001, p.236) define o LEC da seguinte forma: "é a quantidade de pedido de ressuprimento que minimiza a soma do custo de manutenção de estoque e emissão e colocação de pedido".

O modelo de cálculo do LEC considera alguns pressupostos:

- A demanda é considerada conhecida, constante e contínua;

- O lead-time é conhecido e constante;

- Faltas de estoque não são permitidas;

- O preço do produto comprado e o custo de manutenção de estoque são independentes da quantidade;

- Itens são pedidos independentemente, ou seja, não há consolidação de pedidos entre dois produtos diferentes;

- Não existem restrições como transporte, espaço de armazém, dinheiro, etc.

- Todo o pedido chega ao mesmo instante.

O LEC é calculado da seguinte forma:

É definido o custo de manutenção de estoque $(\boldsymbol{C E})$ que é dado pelo produto da quantidade média em estoque e custo da de manutenção de um item no período estimado (h). Assumindo o pressuposto de demanda conhecida e constante durante o período toma-se como quantidade média de estoque a metade do lote de compra $\mathbf{Q}$. Assim tem-se:

$$
C E=(Q / 2) \times h
$$

O custo de emissão de pedidos (CP) no período é dado pela quantidade de pedidos (D/Q) multiplicados pela soma do custo fixo $(\mathbf{F})$ e o variável por unidade pedida $(\mathbf{V} * \mathbf{Q})$. Sendo assim:

$$
C P=(D / Q) \times(F+Q \times v)
$$

O custo total (CT) é dado pela soma destes dois custos:

$$
C T=(Q / 2) \times h+(D / Q) \times(F+Q \times v)
$$

Derivando o custo total em função da quantidade e igualando a equação resultante a zero obtém-se a fórmula que permite o cálculo do lote ótimo: 


$$
\mathrm{LEC}=\sqrt{\frac{2 \times \mathrm{D} \times \mathrm{F}}{\mathrm{h}}}
$$

Os parâmetros do LEC são difíceis de serem estimados. Aqui o conceito de robustez é o que erro de estimativas nos parâmetros não tem um grande impacto no valor final.

Em relação aos seus pressupostos, eles são difíceis de serem encontrados na prática. Para superar parte desta deficiência são realizados alguns cálculos complementares ao LEC para que se tenha um modelo mais próximo da realidade. Esses cálculos não serão discutidos aqui, mais permitiriam calcular um LEC considerando descontos no preço de acordo com a quantidade, permitindo ordens não atendidas, considerando a inflação e outras variações.

Este tipo de método tem como vantagem a simplicidade de implantar e controlar o sistema, no entanto a sua utilização em ambientes de demandas altamente instáveis e imprevisíveis torna-se impraticável, devido aos pressupostos do LEC.

\subsection{Método de revisão contínua, ponto de pedido e nível fixo}

Neste método um nível máximo (M) de estoque é estabelecido e toda vez que a quantidade de itens no estoque contábil atinge o ponto de pedido ou um valor inferior uma nova ordem é emitida com uma quantidade que eleve o valor dos estoques ao nível máximo. Desta maneira a quantidade pedida será dada pela diferença entre o valor máximo estipulado (M) e o nível atual de estoque. Quando a demanda dos clientes é unitária este método se comporta semelhantemente ao anterior, tendo quantidades variáveis nas ordens de compra apenas quando é demandado grande número do mesmo item de uma só vez, de forma que ultrapasse o ponto de pedido.

A principal dificuldade deste método é estipular um nível máximo ótimo. Outra dificuldade também seria a maior incidência de erros na emissão de pedidos devido às quantidades variáveis das ordens.

\subsection{Método de revisão periódica, nível fixo e intervalo fixo entre pedidos}

Neste método de revisão periódica os pedidos de ressuprimento são feitos em intervalos fixos e com quantidades variáveis. Aqui a revisão do estoque é feita em intervalos pré-definidos e então é emitido um pedido com uma quantidade de itens que elevem o estoque a níveis prédeterminados para cada produto ou material. Explicando mais detalhadamente, o gerenciamento dos estoques neste método acontece da seguinte forma: Primeiro estabelece-se um intervalo para ser feita a contagem dos estoques e um nível máximo de estoque para cada item a ser controlado. Então, toda vez que for feita à contagem dos estoques, faz-se um pedido de ressuprimento para os 
itens de forma que eles alcancem o nível máximo de estoque estipulado, conforme cálculo mostrado abaixo.

$$
\begin{aligned}
& \mathrm{Q}=\mathrm{EM}-\mathrm{EA}+\mathrm{DLT} \text {, onde: } \mathrm{Q}=\text { quantidade pedida } \\
& \qquad \begin{array}{l}
\mathrm{EM}=\text { meta de estoque máximo } \\
\mathrm{EA}=\text { nível de estoque atual } \\
\mathrm{DLT}=\text { demanda esperada durante o lead time de ressuprimento }
\end{array}
\end{aligned}
$$

Para estipular o intervalo da revisão dos estoques pode ser utilizada uma abordagem similar ao LEC, onde o intervalo seria o tempo de cobertura de um LEC calculado para este perfil de custo e demanda. Neste caso a fórmula do intervalo econômico de pedidos seria:

$$
\text { Intervalo }=\sqrt{\frac{2 \times \mathrm{F}}{\mathrm{h} \times \mathrm{D}}}
$$

Este modelo é especialmente útil para compra de itens da mesma família ou com o mesmo fornecedor, permitindo coordenar mais facilmente estes itens relacionados.

\subsection{Método de revisão periódica, lote fixo e intervalo fixo entre pedidos}

Esse modelo é bem similar ao descrito anteriormente, tendo a desvantagem de reagir de modo menos eficiente a variações muito elevadas de demanda, visto que, a quantidade a ser pedida é fixa, enquanto que anteriormente era variável.

Assim como no modelo anterior de revisão periódica, umas das tarefas ao se implementar é encontrar um intervalo ideal de revisão. Também é muito útil na tentativa de consolidar cargas, dado que os pedidos são feitos juntos.

\section{Suprimentos}

A função de suprimentos trata do fluxo de materiais dos fornecedores para a firma. Sua importância está no impacto que os custos de materiais exercem sobre o preço final dos produtos e, conseqüentemente, no lucro da organização. Um fator que tem aumentado a preocupação com o suprimento é a crescente automação dos sistemas produtivos, pois além deles derrubarem os custos com mão-de-obra (aumentando a relevância dos custos de materiais), sistemas automatizados normalmente requerem um maior controle de datas de entregas, qualidade do material, etc.

Segundo Ballou (1993, p.59) a motivação de suprimentos "é satisfazer as necessidades dos sistemas de operações, tais como uma linha de produção na manufatura ou um processo operacional de um banco, hospital etc.”. Esta importância de suprimentos nas operações é confirmada com 
Gaither e Frazier (2004) afirmando que sua função é perceber as prioridades competitivas de cada produto importante (baixo custo, entrega rápida e no tempo certo, qualidade, flexibilidade) e desenvolver plano de compra para cada produto que seja coerente com as estratégias de produção. Percebemos também seu forte relacionamento com a produção quando Cervi (2002, p.31) insere na logística de suprimento a função de planejamento e controle da produção com a seguinte afirmação: "A logística de suprimentos, considerada como parte integrante do sistema logístico, envolve os processos de planejamento e programação da produção, emissão e acompanhamento de ordens de compra, recebimento e inspeção de materiais e pesquisa e desenvolvimento de fornecedores".

De acordo com as diversas definições constata-se que os envolvidos com a função de suprimentos precisam entender as necessidades do seu sistema produtivo, analisar a posição da sua empresa na cadeia de suprimentos na qual ela está inserida, para então escolher dentre as várias alternativas de suprimentos aquela que melhor lhe satisfizer. Todas estas atividades devem ter como objetivo garantir que o material certo, esteja no local de operação certo, no momento correto, em boas condições e ao menor custo possível.

\subsection{Preocupações centrais da logística de Suprimento}

A logística de suprimentos precisa responder a alguns questionamentos como: de onde comprar? Como comprar? Por que comprar? Qual a lógica de ressuprimento a ser seguida? Quais etapas devem ser seguidas num processo de compras? Para obter estas respostas ela tem quatro preocupações centrais: transporte do carregamento até o local da fábrica, seleção de fornecedores, emissão e acompanhamento das ordens de ressuprimento, e manutenção dos estoques de matériaprima dentro na planta de fabricação.

As decisões de transporte envolvem basicamente questões de responsabilidade pela movimentação do produto do fornecedor até a empresa (ou seja, se o transporte está ou não incluído no contrato de compra) e a escolha do tipo de modal, sempre considerando o custo médio do serviço, o tempo médio de entrega, variabilidade no tempo de entrega e as perdas e danos nos materiais causados pelo transporte.

Nas tarefas de seleção dos fornecedores serão considerados quesitos como preço, qualidade, confiança para possíveis parceiras, flexibilidade de entrega, localização. A localização dos fornecedores é um fator importante porque afetam o prazo e a confiabilidade das entregas, parâmetros que influenciam nos níveis de estoques de segurança. Outro fator importante é que selecionar fornecedores próximos entre si facilita a consolidação de cargas.

Sendo os sistemas produtivos os clientes da logística de suprimentos, serão as características deles que vão definir o momento da emissão de uma ordem de suprimento, bem como as formas de acompanhamento destas. São informações indispensáveis numa ordem de ressuprimento: descrição 
clara e precisa do material desejado (tipo e qualidade), quantidade, local de entrega e data de entrega. Segundo Ballou (1993, p.63) as ordens de fornecimento é documento primordial para o fluxo de produtos no canal de fornecimento: "O processo de compras e as ordens resultantes estabelecem o volume de produtos a serem movidos e estocados no sistema logístico em dado instante. Coordenação falha entre os processos de compras e de movimentação de produtos pode levar a custos logísticos desnecessários”. Mais adiante será visto como as ordens de produção são emitidas nos diversos sistemas de produção.

Da mesma forma que a emissão de ordem de fornecimento, a manutenção de estoques dentro da fábrica vai depender muito das características do sistema produtivo. Fatores que têm relação com a política de estoque para matérias-prima são: o tipo de sistema de administração da produção e as características do material como preço, perecibilidade, facilidade de fornecedor etc. Em geral as matérias-primas são divididas em dois grupos, material de estoque e material entregue direto na produção.

No suprimento de materiais de estoques as políticas de estoques é que determinam o momento de emissão de ordens de ressuprimentos. Ballou (1993) apresenta algumas características da matéria-prima que nos fazem tender a colocar um material no grupo gerido por políticas de estoques:

- Ser comprado em quantidades maiores ou iguais a um lote mínimo;

- Tabela de preço do fornecedor contém desconto por quantidade;

- Ser de valor relativamente baixo;

- Ser econômico comprá-lo junto de outros itens;

- Ser usado numa larga variedade de modelo;

- Ter tabela de fretes que facilitem a compra em grandes lotes;

- Ter alto grau de incerteza na entrega ou na continuidade do ressuprimento.

No caso de materiais entregues diretos para produção, a idéia é evitar os custos de manutenção de estoques fazendo pedido apenas quando necessário, sendo necessário para isto um considerável esforço no sentido de melhorar a comunicação com fornecedores, estabelecer parcerias com eles e diminuir o lead-time de entrega das matérias-prima. Características de materiais que induzem a essa postura são um alto valor individual e demanda pequena e instável na produção. Essa discussão sobre estoques também acontecerá algumas vezes quando for escrito sobre os sistemas de administração da produção. 


\section{Simulação}

\subsection{Características, Benefícios e Aplicações}

Após terem sidos abordados aspectos que envolviam a Cadeia de Suprimentos, importância e modelos de estoques além do relacionamento dos suprimentos com os sistemas produtivos, serão abordados agora conceitos sobre simulação e características da ferramenta utilizada no estudo de caso, o @Risk.

Saliby (1999, p. 2) entende que "a Simulação consiste no processo de construção de um modelo que replica o funcionamento de um sistema real ou idealizado e na construção de experimentos computacionais com esse modelo com o objetivo de melhor entender o problema em estudo".

Pode-se definir um sistema como um conjunto de entidades que se relacionam para cumprir um determinado fim. Estas entidades têm associadas a si atributos que carregam as características das mesmas.

Segundo Sterman (2000, p. 202), “o estado de um sistema pode ser definido pela situação das entidades que o constituem, caracterizada quer em termos dos valores dos atributos quer das relações de associação entre as entidades." Estas alterações de estado podem ser de caráter contínuo no tempo ou em instantes isolados de tempo que podem ser discretizadas. A abordagem a ser utilizada no caso prático deste trabalho contemplará alterações discretas.

O questionamento que prossegue é porque utilizar a simulação como forma de estudar impactos, dadas diferentes alterações provocadas nesse sistema. Um dos motivos é quando há a necessidade de tomada de decisões sobre, por exemplo, quando pedir ressuprimento e em qual quantidade e não se têm como quantificar a priori quais impactos dessas variáveis dentro do sistema em estudo. Em situações como essa, a simulação é uma das ferramentas indicadas por permitir a análise do desempenho com as alterações propostas.

De acordo com Pidd (2003) a simulação permite ultrapassar muitas das limitações de modelos analíticos dado que permite a modelagem de comportamentos de sistemas com alto grau de complexidade além de poder modelar fatores aleatórios que inviabilizariam uma modelagem analítica.

As aplicações dentro da logística são as mais variadas podendo destacar estudos sobre dimensionamento de estoques, análises sobre estruturas de armazenagem e a movimentação de materiais, análises sobre a produção e os seus impactos.

O sucesso de uma modelagem está na definição exata dos objetivos de cada uma das fases do projeto. Adaptando estruturas propostas por Saliby (1999) e Wanke (2003) pode-se definir uma estrutura genérica a ser abordada em estudos de simulação. 
1. Levantamento de informações / Entendimento do Problema

2. Modelagem Conceitual

3. Modelagem Matemática

4. Validação do Modelo

5. Elaboração de Lista de Experimentos

6. Análise de Cenários

A primeira fase da metodologia proposta envolve um árduo entendimento do sistema a ser abordado, dado que existe a necessidade do perfeito entendimento do problema ou da situação atual do sistema de modo a servir como subsídio para as etapas 2 e 3 . Outro ponto existente na primeira etapa e de suma importância é o levantamento de informações que entra no modelo nas fases subseqüentes como input de dados.

A modelagem conceitual, como já dito, aborda o entendimento da situação em questão e nada mais é que um desenho do sistema de modo a embasar a modelagem matemática já na etapa seguinte.

A validação do modelo pode ser definida como uma etapa crucial para o projeto, dado que ela vai mostrar se o modelo está calibrado ou não com a realidade histórica e possibilitar sua utilização para as análises desejadas. Caso não haja a possibilidade de reproduzir o chamado "caso base" a validação parte para o lado intuitivo sendo executada por meio de indicadores de saída do modelo como aborda Wanke (2003).

Com a lista de experimentos a ser testada já elaborada, entra-se na fase de análise de cenários que é a mais rica em estudos desse tipo. São testadas as situações especificadas na lista de experimentos que geralmente incluem fatos que possivelmente serão enfrentadas pelo sistema em questão (como por exemplo, aumento da demanda nos próximos anos) ou mesmo possibilidade de alteração de padrões vigentes (mudança do intervalo de ressuprimento, por exemplo). No final, o resultado deve apontar o que ocorre com o sistema (compilação dos outputs) dado as mudanças propostas.

Um último ponto a ser destacado é que a condução de um experimento de simulação implica na necessidade de algumas capacitações, como por exemplo, conhecimento do software a ser usado na modelagem assim como razoável conhecimento estatístico de modo a trabalhar os dados imputados no modelo assim como a compilação de estatísticas de desempenho e interpretação de resultados. 


\subsection{Descrição do @Risk e suas funcionalidades}

Como já citado no começo deste capítulo, a ferramenta a ser utilizada no estudo de caso é o @ Risk, software fabricado pela Palisade, e utilizado no formato de um "add-in" em parceria com o Microsoft Excel. Vale ressaltar que os pontos abordados nesta sessão são os pontos principais e que serão utilizados no estudo de caso.

Juntamente com o @ Risk são incorporadas ao Microsoft Excel alguns novos grupos de funções como funções de distribuição, funções de estatísticas, dentre outras que serão melhor abordadas posteriormente.

A utilização do @ Risk se justifica pelo fato de que a estimativa de variáveis nas quais possa haver risco pode-se levar a vieses otimistas ou pessimistas, comprometendo a análise e consequentemente a tomada de decisão. A modelagem no @Risk combina as incertezas e não obriga o usuário a reduzir o conhecimento sobre uma variável em um só número.

De modo mais técnico, pode-se resumir que os diferenciais do @ Risk que proporcionam a modelagem são:

- Entrada de Dados por meio de distribuições de Probabilidade;

- Métodos amostrais capazes de reproduzir as distribuições citadas;

- Ferramentas que possibilitam confecção/análise dos resultados.

\section{Estudo de Caso}

\subsection{Descrição da Empresa / Caracterização do Problema}

A empresa selecionada para este estudo tem como foco as atividades de fabricação e distribuição de bebidas, sendo que seu nome não pode ser identificado por sigilo dos dados utilizados. A sua cadeia logística pode ser resumida pela Figura 5: 


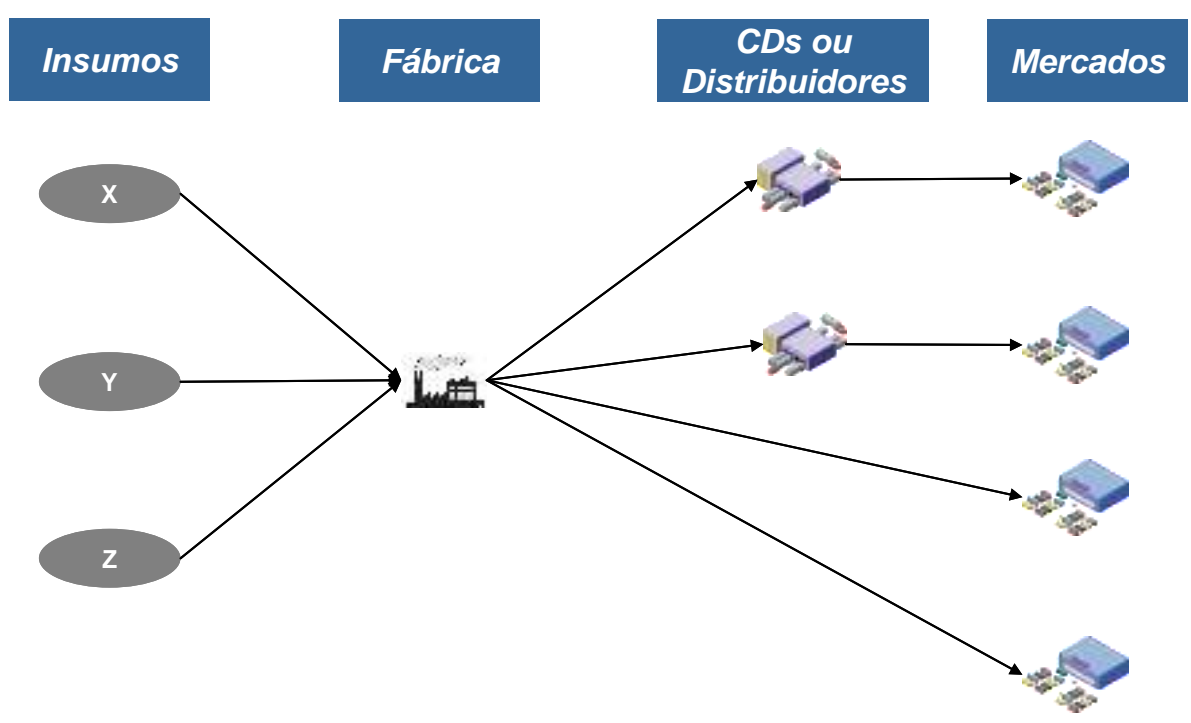

Fonte: Os autores (2008)

Pela Figura 5, entende-se que a fábrica processa as matérias primas advindas dos fornecedores de modo a atender a demanda dos mercados (diretamente ou por intermédio dos distribuidores).

Um dos grandes problemas que a fábrica está passando é a gestão dos seus estoques de matérias primas. Ocorrências de falta de itens nos estoques estão se tornando freqüentes e surge com isso a necessidade de se estudar novas políticas para a administração dos mesmos de modo a se balancear as quantidades estocadas com a demanda. Sabe-se que a falta de itens no estoque afeta diretamente a produção que pode se tornar incapaz de produzir os itens demandados, podendo impactar diretamente o cliente final.

Outro ponto relativo à produção é que dado aos inúmeros SKUs e suas diferentes características a programação de setups é muito importante e a falta de insumos para entrar no processo produtivo desorganiza o planejamento de setups que tem de ser refeito gerando custos adicionais.

Com isso as perguntas a serem respondidas por esse estudo de caso são:

- Com qual freqüência deve ser avaliado o nível dos estoques?

- Quando um pedido de reposição deve ser colocado?

- Quantas unidades devem ser pedidas?

- Qual nível de serviço esperado com a definição das variáveis acima descritas? 
A estratégia a ser utilizada para responder estas questões passar por testar alguns modelos de estoques para as matérias primas e demonstrar o quão eficiente cada um pode ser. Os testes serão executados no Microsoft Excel com o auxílio de simulação com o @ Risk (já descrito no capítulo 5).

\subsection{Obtenção de Informações}

Analisando a base de dados das matérias primas, visualiza-se a princípio uma divisão em dois grandes grupos, insumos com baixo coeficiente de variação da demanda e outros com alto coeficiente de variação da demanda. Essa segmentação pode ser útil dado que pode contribuir a entender as respostas dos modelos a serem testados, visto que alta variabilidade da demanda implica em altos estoques de segurança e consequentemente altos custos de estoques.

A base de demanda das matérias primas tem o horizonte de 52 semanas. Outras informações presentes na base são o custo de aquisição unitário, o histórico de lead times e estoque médio registrado do período citado. A primeira segmentação realizada na base de modo a escolher os pilotos para os testes foi verificar a existência de demanda nas 52 semanas. Posteriormente foram selecionadas duas matérias primas com coeficiente de variação da demanda menor que 0,5 e outras duas com coeficiente de variação maior que 0,5 , que irão compor o piloto de testes desse estudo de caso.

O coeficiente de variação é definido pela divisão do desvio padrão pela média da série de dados em questão e tem como objetivo identificar se existe alta variabilidade dos dados analisados.

A Tabela 1 mostra os coeficientes de variação das demandas.

Tabela 1 - Coeficiente de Variação das Demandas das Matérias Primas

\begin{tabular}{|c|c|}
\hline MATERIAL & CV \\
\hline MATÉRIA PRIMA 1 & 0,33 \\
\hline MATÉRIA PRIMA 2 & 0,30 \\
\hline MATÉRIA PRIMA 3 & 0,70 \\
\hline MATÉRIA PRIMA 4 & 0,60 \\
\hline
\end{tabular}

Fonte: Os Autores (2008)

Nos gráficos é claramente perceptível que as MP 1 e 2 possuem as demandas semanais não muito descoladas da média, enquanto que a MP 3 tem alguns valores bem descolada da média e a MP 4 que aparentemente não possui a demanda muito oscilante (que está mascarada pela escala do gráfico) e alguns picos bem elevados.

Atualmente o processo de reposição do estoque não segue nenhuma política clara e bem definida. Os pedidos são colocados de modo que possam cobrir a demanda das semanas seguintes e 
essa prática não parametrizada e definida faz com que ocorram faltas e outras vezes excesso de estoque demonstrando um desbalanceamento.

Assumindo a premissa de taxa de oportunidade de capital a $15 \%$ ao ano juntamente com os valores de estoque médio, custos de aquisição unitário e demanda média histórica contidos na base pode-se construir um gráfico retratado na Figura 6:

Figura 6 - Gráfico Cobertura x Custo de Oportunidade do Estoque

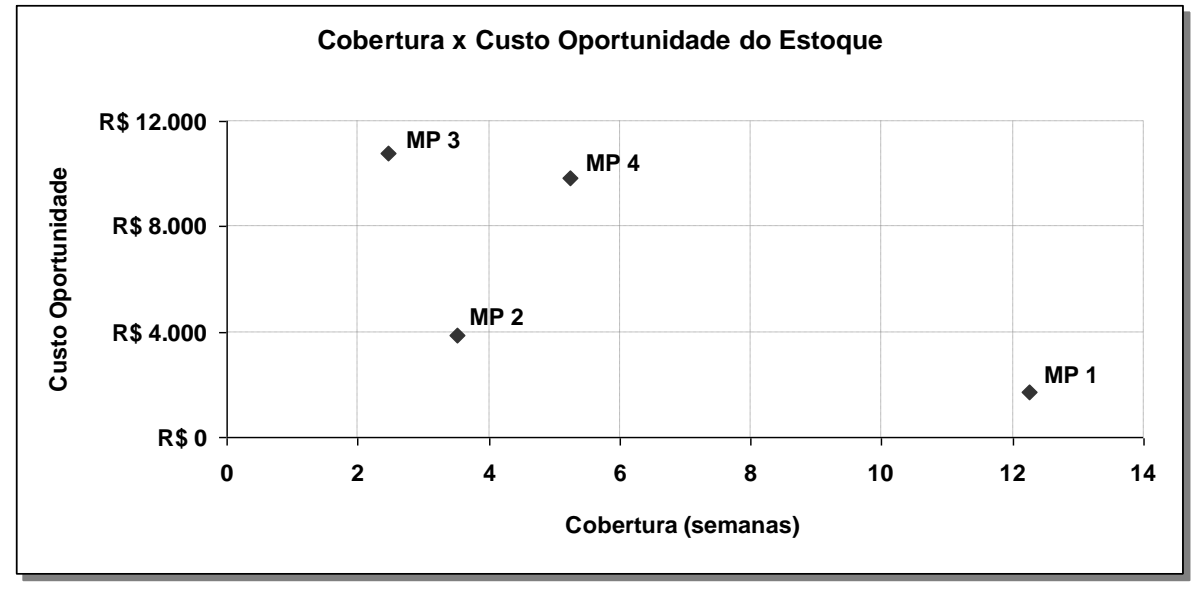

Fonte: Os autores (2008)

Visualiza-se valores intermediários de cobertura de estoque para as MPs 2,3 e 4, com um custo de oportunidade maior para a MP3 e cobertura alta para a MP1 associada a um baixo custo de oportunidade de mantê-la em estoque.

Outra conclusão a ser tirada, já que o Giro dos Estoques é o inverso da Cobertura, temos que a MP 1 é que menos gira (4,2 vezes ao ano) dada a sua alta cobertura, enquanto que a MP 3 é que mais gira $(21,1$ vezes ao ano).

A pergunta que segue é se esses valores de giro e coberturas estão proporcionando bons níveis de serviço? Como já mapeado no início da descrição do caso, aparentemente não e a resposta das simulações dos modelos vai indicar valores que satisfaçam os níveis de serviços desejados.

\subsection{Escolha dos Modelos a serem testados}

Com os pilotos escolhidos, parte-se para selecionar os modelos a serem testados na simulação. Os selecionados (e já detalhados no capítulo 3) foram:

- Revisão Contínua, Ponto de Pedido e Lote Econômico de Compra;

- Revisão Contínua, Ponto de Pedido e Nível Fixo (M);

- Revisão Periódica, Nível Fixo (M) e Intervalo Fixo entre os Pedidos (R); 
- Revisão Periódica, Intervalo Fixo entre Pedidos (R) e Lote Q.

A lógica implementada no Excel/@Risk para cada modelo é ilustrada nas Figuras 7, 8, 9 e 10.

Figura 7 - Modelo de Revisão Contínua, Ponto de Pedido e Lote Econômico de Compra

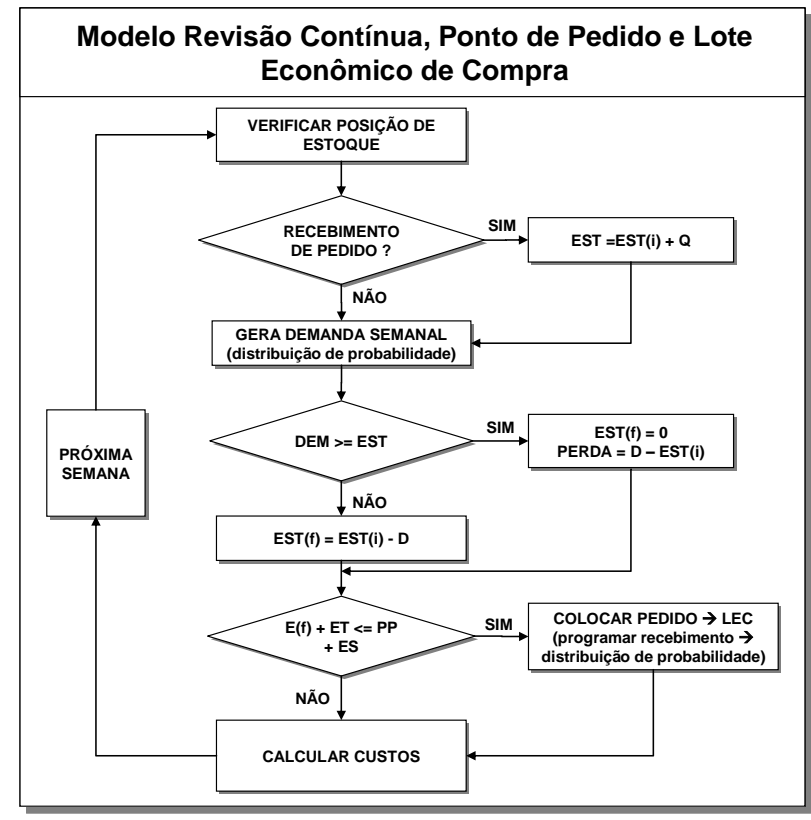

Fonte: Os autores (2008)

Figura 8 - Modelo de Contínua, Ponto de Pedido e Teto Fixo (M).

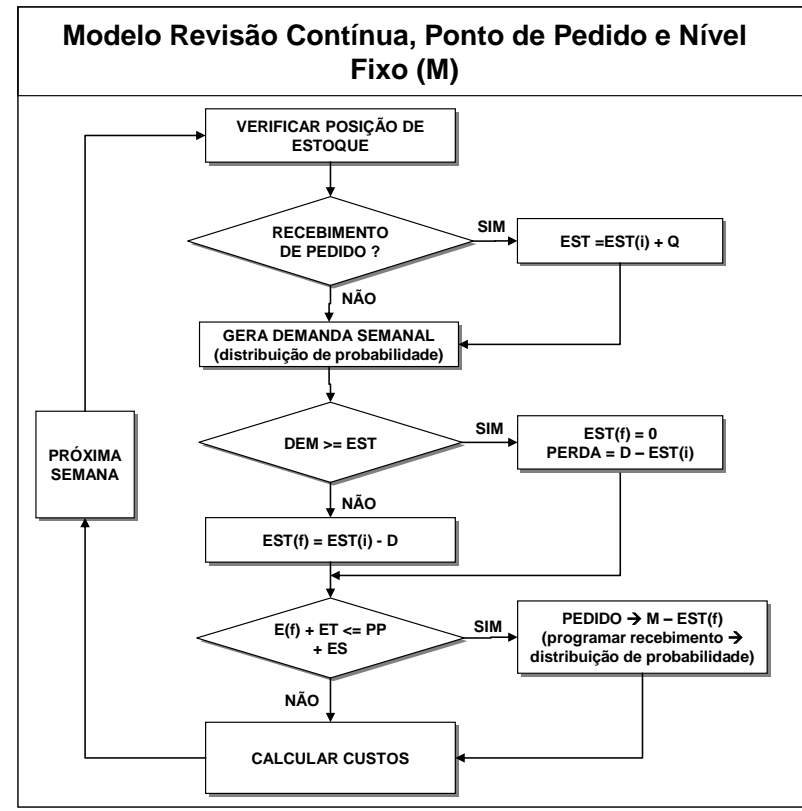

Fonte: Os autores (2008) 
Figura 9 - Modelo de Revisão Periódica com Nível Fixo (M) e Intervalo Fixo entre Pedidos (R)

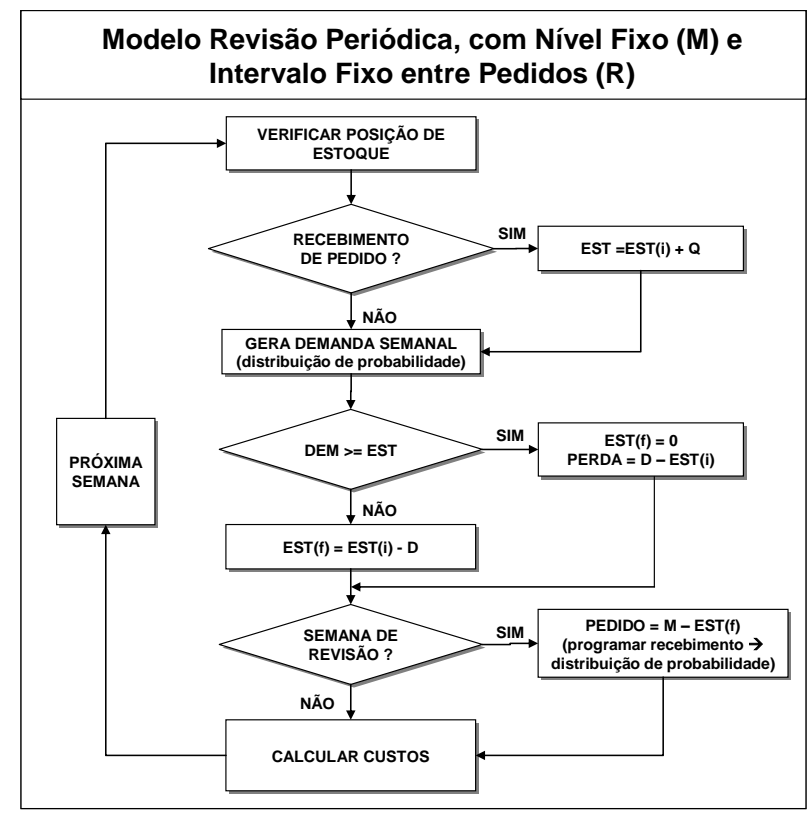

Fonte: Os autores (2008)

Figura 10 - Modelo de Revisão Periódica com Intervalo Fixo entre Pedidos (R) e lote Fixo Q

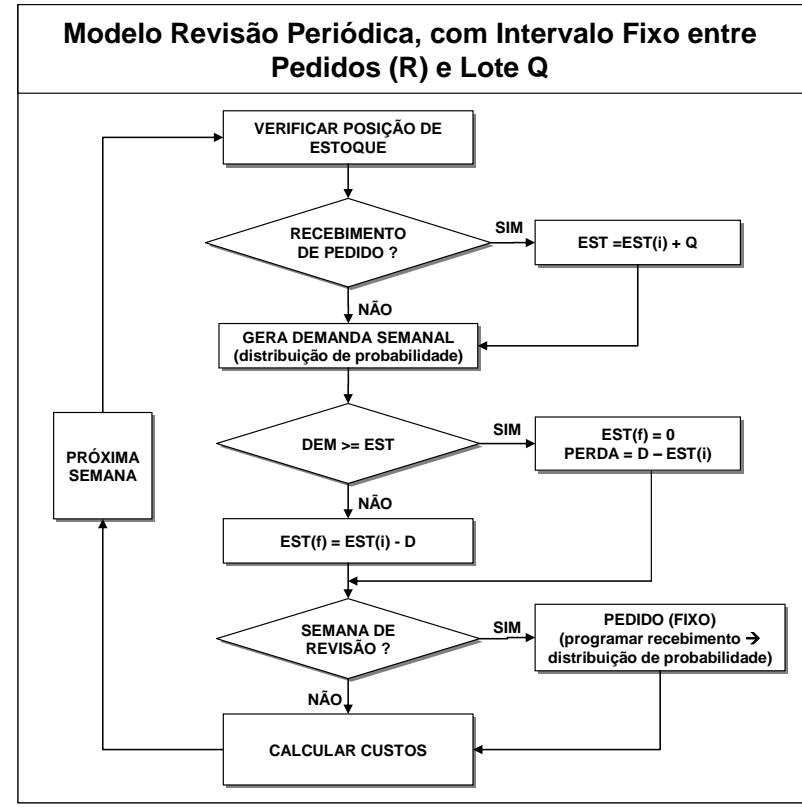

Fonte: Os autores (2008)

\subsection{Construção do Modelo}

Com os pilotos para a análise já selecionados juntamente com a definição dos modelos de estoque, parte-se para a construção do modelo de simulação que vai ser à base deste estudo de caso.

O problema já foi mapeado/entendido e as informações levantadas, faltando tratar algumas delas de modo que possam servir de input ao modelo de simulação. Há a necessidade de se obter a 
distribuição de probabilidade da demanda das MPs assim como a distribuição de probabilidade do lead time de fornecimento das MPs.

A distribuição da demanda foi obtida utilizando a ferramenta de fitagem presente no @Risk. As demanda históricas são as entradas e a saída é uma lista de distribuições aderentes ao conjunto de dados. Essa lista foi "rankeada" pelo teste KS (Kolmogorov-Smirnov) e os resultados são mostrados nas Figuras 11, 12, 13 e 14.

Figura 11 - Distribuição de Probabilidade da Demanda da MP 1

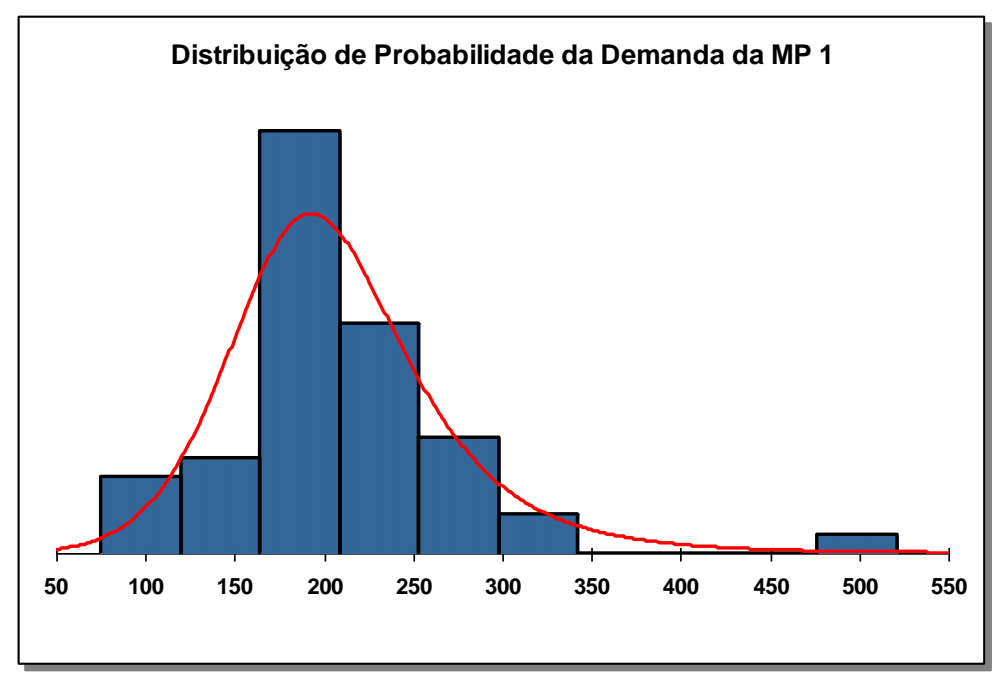

Fonte: Os autores (2008)

Figura 12 - Distribuição de Probabilidade da Demanda da MP 2

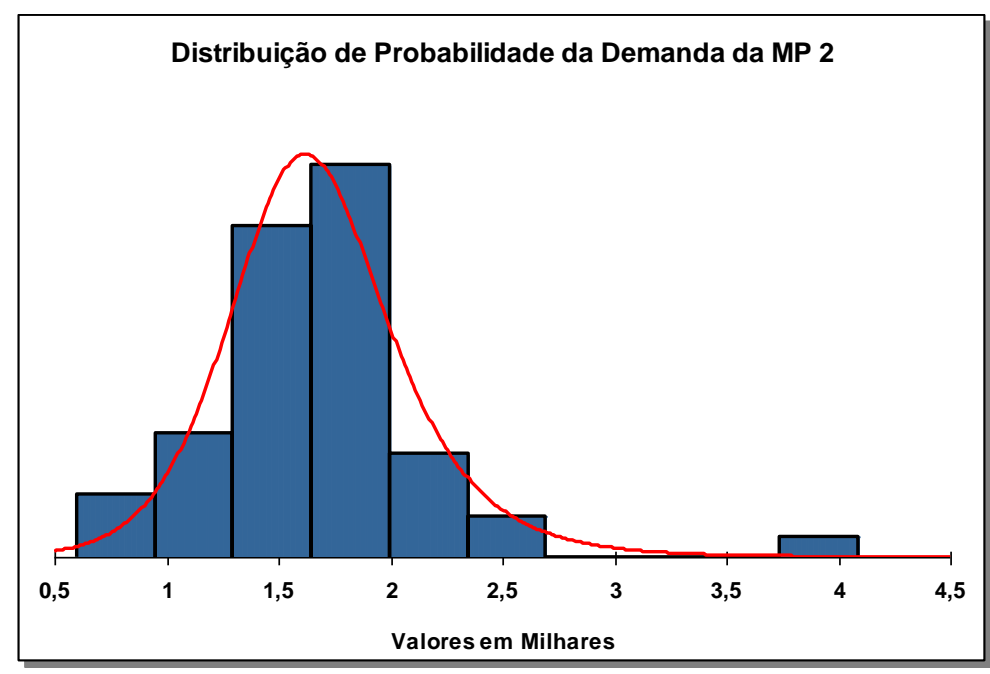

Fonte: Os autores (2008) 
Figura 13 - Distribuição de Probabilidade da Demanda da MP 3

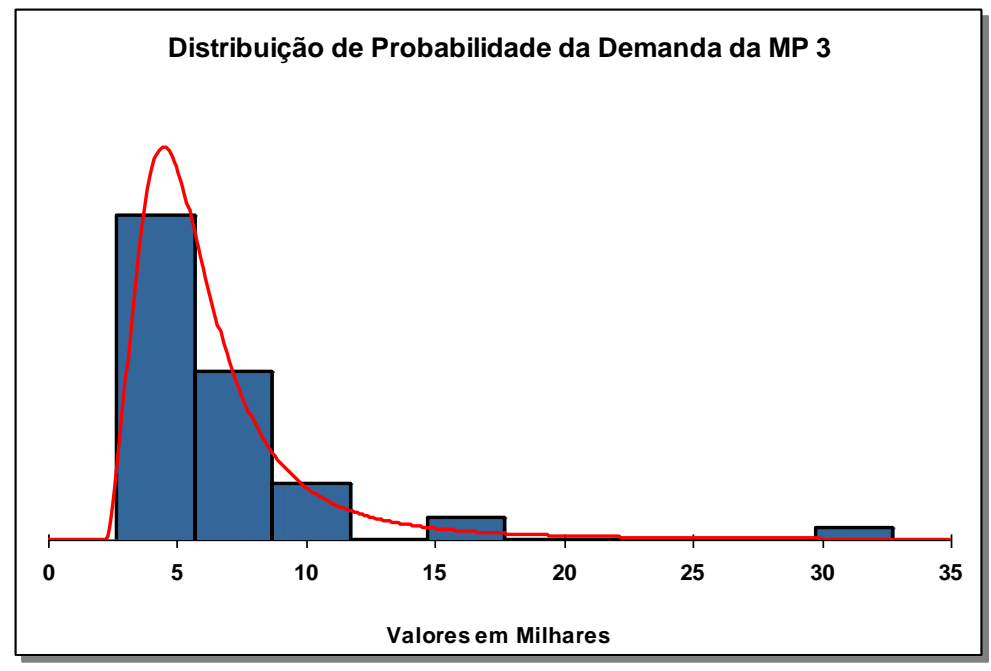

Fonte: Os autores (2008)

Figura 14 - Distribuição de Probabilidade da Demanda da MP 4

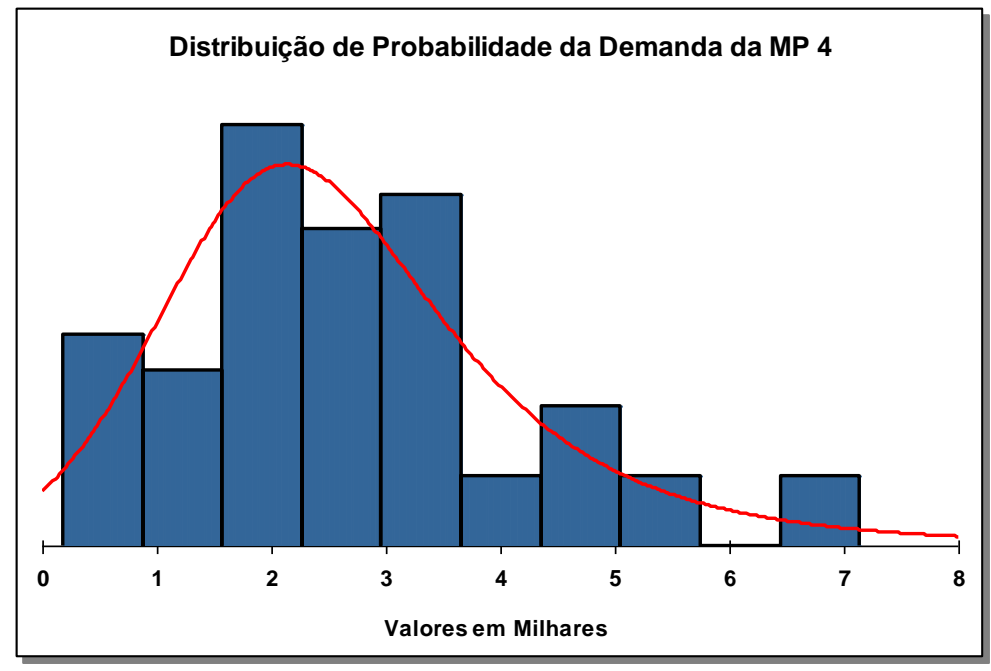

Fonte: Os autores (2008)

Todas as quatro matérias primas foram aderentes a distribuição LogLogistic (@Risk). Os parâmetros gamma, beta e alfa das distribuições são observados na Tabela 2.

Tabela 2 - Parâmetros das Distribuições

\begin{tabular}{|c|c|c|c|}
\hline MP & Gamma & Beta & Alfa \\
\hline MP 1 & $-64,482$ & 265,61 & 7,9791 \\
\hline MP 2 & -1675 & 3327,7 & 14,221 \\
\hline MP 3 & 2269,3 & 32059 & 2,402 \\
\hline MP 4 & $-2328,9$ & 4773,6 & 5,5398 \\
\hline
\end{tabular}

Fonte: Os autores (2008) 
Para o custo de colocação de pedidos foi assumida a premissa de que esse valor seria $\mathrm{R} \$$ 80,00 por pedido que corresponde ao custo do setor de compras da empresa dividido pela quantidade de pedidos de compra realizados no horizonte de tempo abordado no estudo. As distribuições de probabilidade dos lead times foram assumidas como normais com parâmetros contidos na base de dados.

A segunda etapa do processo é a modelagem conceitual que nada mais é do que raciocinar em cima do problema na gestão dos estoques já mapeado e estruturar a maneira pela qual a modelagem matemática será feita.

Com a estrutura dos modelos já definidos e os dados de entrada já modelados, fica apenas a pendência de definir quais indicadores serão utilizados como parâmetros para os resultados do modelo. Essa definição segue abaixo:

- Estoque Médio

- Quantidade de Pedidos

- Quantidade Média de Falta

- Nível de Serviço

- Custo Total da Política (Custo de Estoque + Custo de Colocação de Pedido)

A terceira etapa é o entendimento da estrutura dos quatro modelos propostos e a programação das suas lógicas no Excel e no @Risk, utilizando as funções próprias do Excel e outras, como por exemplo, as funções de distribuição de probabilidade, provenientes do @ Risk.

A quarta etapa da modelagem é a validação do modelo desenhado. Antes de executar a validação, é necessário executar um teste de robustez de modo a identificar qual o número ideal de iterações para rodar as simulações. Essa definição de iterações faz com que se tenha certeza que qualquer alteração nos resultados tenha ocorrido se e somente se por variações nos inputs e nunca por uma quantidade inadequada de iterações.

Após ter calculado deterministicamente o Lote Econômico e o Ponto de Pedido para a MP1 e ter calibrado o modelo com os parâmetros desse item e desse modelo de estoque, foram rodadas simulações com número crescente de iterações de modo a encontrar um número nos quais os resultados do modelo não variem muito em relação ao número anterior. 


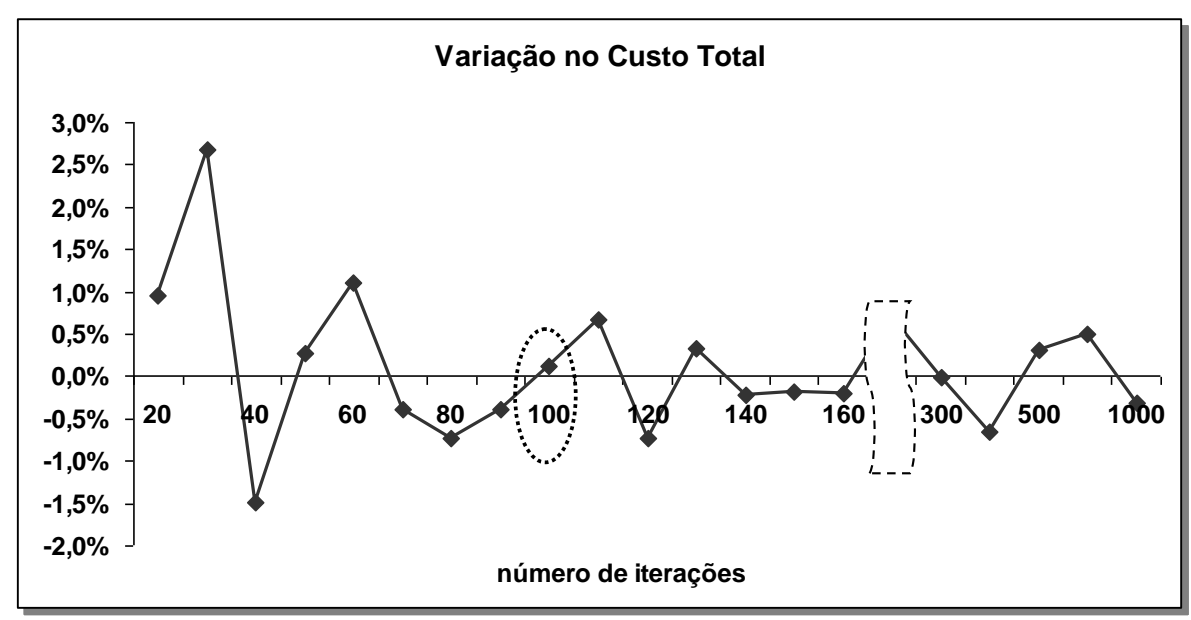

Fonte: Os autores (2008)

Percebe-se pela Figura 15 que depois de 100 iterações os resultados de Custo Total variam em torno de 0,5\% em relação ao resultado obtido com 10 iterações a menos. Essa variação foi considerada aceitável e 100 iterações foi definido como sendo ideal para o modelo em questão.

Agora se pode executar uma rodada e tentar a validação do modelo. Esta tarefa não é muito trivial já que não se tem um caso base pra se executar uma comparação direta e validar ou invalidar o modelo. A solução encontrada foi utilizar os valores já calculados para o teste de robustez e variar o tamanho do Lote de modo a identificar as mudanças nos indicadores de desempenho e verificar se as mesmas fazem sentido.

Figura 16 - Análise de Validação do Modelo

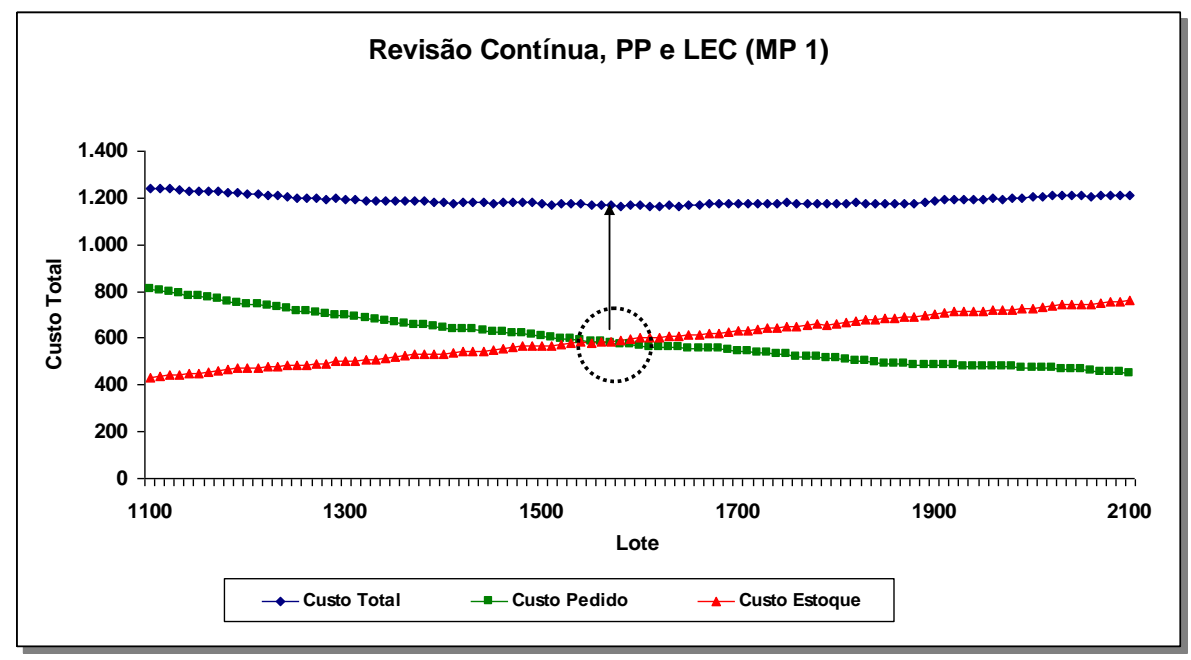

Fonte: Os autores (2008) 
A Figura 16 mostra que a MP1 é bem aderente ao modelo LEC,PP (vale lembrar que essa MP possui baixo CV da demanda), e a variação do lote forma a curva clássica que mostra o tradeoff entre custo de estoque e custo de pedido.

É perceptível que quando se aumenta o tamanho do lote é necessária uma menor quantidade de pedidos (menor custo de pedido) e aumenta-se o estoque médio (aumentando o custo de estocagem). Ao passo que se diminui o tamanho do lote essa relação se estabelece de maneira inversa.

Outra validação importante é que o modelo está seguindo a lógica de colocação de pedidos, ou seja, quando o estoque final do período somado ao estoque em trânsito é menor que o Ponto de Pedido mais o Estoque de Segurança, um pedido de Lote Econômico é disparado.

Com o modelo já validado, pode-se elaborar a lista de cenários a serem rodados e analisados.

\section{5 - Análise de Cenários}

A lista de cenários a ser testada é composta pela simulação das 4 MPs nos quatro modelos propostos e a realização de algumas análises de sensibilidade.

Um dos principais inputs para rodar alguns cenários é o calculo do Lote Econômico de Compra, que pode ser visualizado na Tabela 3.

Tabela 3 - Valores de Lote Econômico para as MPs em unidades.

\begin{tabular}{|c|c|}
\hline MATERIAL & LEC \\
\hline MP 1 & 1.618 \\
MP 2 & 4.624 \\
MP 3 & 9.205 \\
MP 4 & 5.626 \\
\hline
\end{tabular}

Fonte: Os autores (2008)

\subsection{1 - Modelo de Revisão Contínua, Ponto de Pedido e Lote Econômico}

A aplicação da política LEC,PP só teve como resposta bons níveis de serviço nas MPs 1 e 2 . Nos outros dois casos a política proporcionou serviços menos eficientes. Vale lembrar as que as MPs de baixo desempenho tem as suas demandas com altos coeficientes de variação e que isto fere umas das premissas mais fortes da política aplicada que é a estabilidade da demanda. 


\begin{tabular}{|c|c|c|c|c|}
\hline Indicadores & MP1 & MP2 & MP3 & MP4 \\
\hline Estoque Médio & 911 & 3.082 & 12.156 & 4.434 \\
\# Pedidos & 7 & 18 & 32 & 22 \\
Qtde Media Falta & 1 & 68 & 571 & 269 \\
Nivel de Servico & $98,3 \%$ & $92 \%$ & $90 \%$ & $87 \%$ \\
Custo Estoque & $\mathrm{R} \$ 604$ & $\mathrm{R} \$ 2.020$ & $\mathrm{R} \$ 7.968$ & $\mathrm{R} \$ 3.113$ \\
Custo Pedido & $\mathrm{R} \$ 562$ & $\mathrm{R} \$ 1.421$ & $\mathrm{R} \$ 2.555$ & $\mathrm{R} \$ 1.780$ \\
Custo Total & $\mathrm{R} \$ 1.166$ & $\mathrm{R} \$ 3.441$ & $\mathrm{R} \$ 10.524$ & $\mathrm{R} \$ 4.893$ \\
\hline
\end{tabular}

Fonte: Os autores (2008)

Como análise de sensibilidade, foi usada a ferramenta Goal Seek do @Risk, provocando alterações nos Lotes Econômicos de modo a encontrar valores que possam proporcionar melhores níveis de serviço.

Como se pode observar pela Figura 17 a sensibilidade indicou que tamanhos de lote maiores proporcionam elevados níveis de serviços, contudo o custo de oportunidade dos estoques aumenta exponencialmente. Esse comportamento foi similar para as 4 MPs.

Figura 17 - Trade-off Serviço x Custo de estoque MP 1
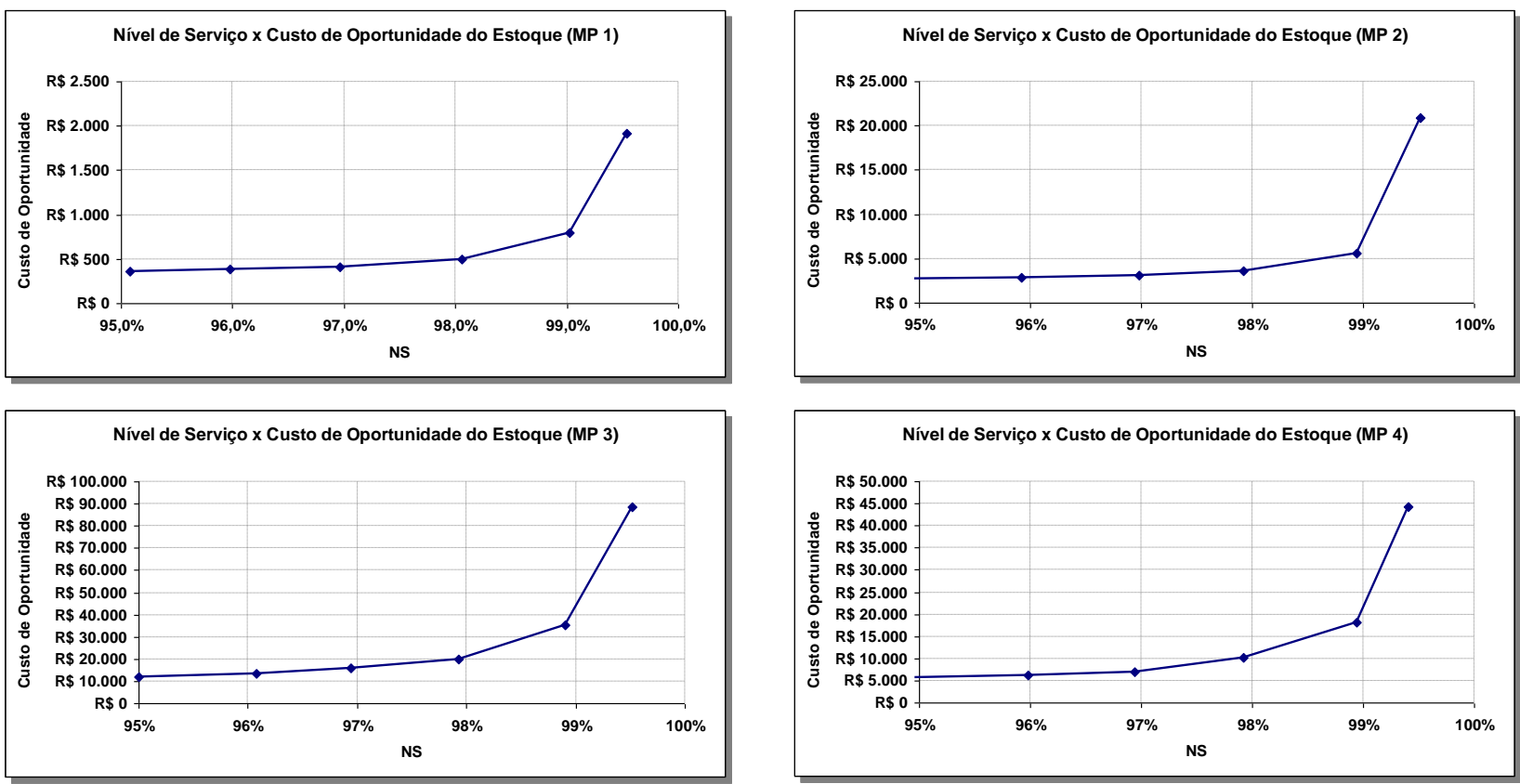

Fonte: Os autores (2008)

A Tabela 5 mostra os indicadores das quatro MPs para nível de serviço igual a $95 \%$. 
Tabela 5 - Resultado da Sensibilidade de Nível de Serviço para 95\%

\begin{tabular}{|c|c|c|c|c|}
\hline Indicadores & MP1 & MP2 & MP3 & MP4 \\
\hline Estoque Médio & 543 & 4.236 & 18.168 & 8.144 \\
\# Pedidos & 11 & 11 & 20 & 11 \\
Qtde Media Falta & 5 & 40 & 312 & 100 \\
Nivel de Servico & $95 \%$ & $95 \%$ & $95 \%$ & $95 \%$ \\
Custo Estoque & $\mathrm{R} \$ 360$ & $\mathrm{R} \$ 2.776$ & $\mathrm{R} \$ 11.909$ & $\mathrm{R} \$ 5.717$ \\
Custo Pedido & $\mathrm{R} \$ 911$ & $\mathrm{R} \$ 906$ & $\mathrm{R} \$ 1.564$ & $\mathrm{R} \$ 908$ \\
Custo Total & $\mathrm{R} \$ 1.271$ & $\mathrm{R} \$ 3.683$ & $\mathrm{R} \$ 13.473$ & $\mathrm{R} \$ 6.625$ \\
\hline
\end{tabular}

Fonte: Os autores (2008)

A Tabela 6 compara os estoques médios atuais (presentes na base de dados) com os obtidos na sensibilidade de serviço para 95\%. Observa-se uma redução em todas as MPs, exceto para a MP três que tem um aumento de $10 \%$. Essa redução em estoque médio é uma diminuição direta no custo de oportunidade em manter estoques.

Tabela 6 - Comparação dos Estoques Médios

\begin{tabular}{|c|c|c|c|}
\hline MP & EM Atual & EM (com NS 95\%) & Redução \\
\hline MP 1 & 2.558 & 543 & $371 \%$ \\
MP 2 & 5.911 & 4.236 & $40 \%$ \\
MP 3 & 16.438 & 18.168 & $-10 \%$ \\
MP 4 & 14.004 & 8.144 & $72 \%$ \\
\hline
\end{tabular}

Fonte: Os autores (2008)

\subsection{2 - Modelo de Revisão Contínua, Ponto de Pedido e Nível Fixo M}

Esta política proporcionou maiores níveis de serviço, como pode ser observado na Tabela 7.

Tabela 7 - Resultados Rev. Cont. Ponto de Pedido e Nível Fixo M

\begin{tabular}{|c|c|c|c|c|}
\hline Indicadores & MP1 & MP2 & MP3 & MP4 \\
\hline Estoque Médio & 970 & 3.898 & 23.243 & 6.894 \\
\# Pedidos & 7 & 12 & 15 & 14 \\
Qtde Media Falta & 2 & 68 & 240 & 146 \\
Nivel de Servico & $98,5 \%$ & $92 \%$ & $96 \%$ & $93 \%$ \\
Custo Estoque & $\mathrm{R} \$ 643$ & $\mathrm{R} \$ 2.555$ & $\mathrm{R} \$ 15.236$ & $\mathrm{R} \$ 4.840$ \\
Custo Pedido & $\mathrm{R} \$ 537$ & $\mathrm{R} \$ 951$ & $\mathrm{R} \$ 1.183$ & $\mathrm{R} \$ 1.122$ \\
Custo Total & $\mathrm{R} \$ 1.180$ & $\mathrm{R} \$ 3.506$ & $\mathrm{R} \$ 16.419$ & $\mathrm{R} \$ 5.962$ \\
\hline
\end{tabular}

Fonte: Os autores (2008) 
Essa diferença em relação ao modelo anterior pode ser explicada pelo fato de que a quantidade de reposição solicitada não estar vinculada ao Lote Econômico e sim a diferença entre o estoque existente e o teto definido.

A mesma análise de sensibilidade proposta anteriormente foi feita em cima desse modelo, demonstrando o caráter crescente e exponencial do custo de estoque dado o aumento de NS.

\subsection{3 - Comparação entre as políticas de Revisão Contínua}

Com as sensibilidades simuladas e os indicadores compilados pode-se elaborar uma comparação entre as duas políticas abordadas até o momento de modo a tentar identificar algumas diferenças de custos entre elas.

Para as matérias primas 3 e 4 (Figura 18) praticamente não houve diferenças em relação ao Custo Total das políticas simuladas conforme ia sendo alterado a "meta" de nível de serviço no Goal Seek.

Figura 18 - Comparação entre as Políticas de Revisão Contínua para a MP 3 e MP4
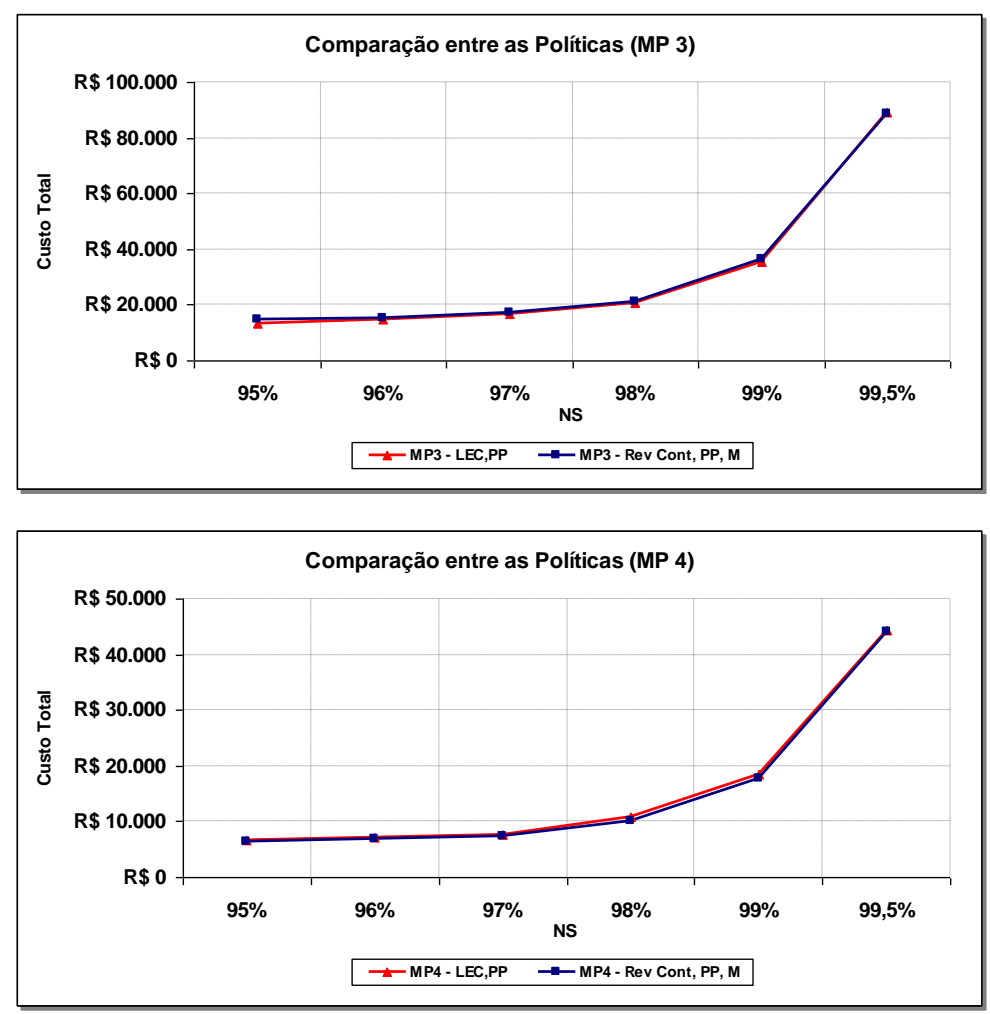

Fonte: Os autores (2008)

Fazendo a mesma análise para as MPs 1 e 2 (Figura 19) já são perceptíveis algumas diferenças em custo principalmente nos níveis de serviço mais elevados, o que levaria a princípio a decisão para a política de menor custo total. 
Figura 19 - Comparação entre as Políticas de Revisão Contínua para a MP 1 e MP2
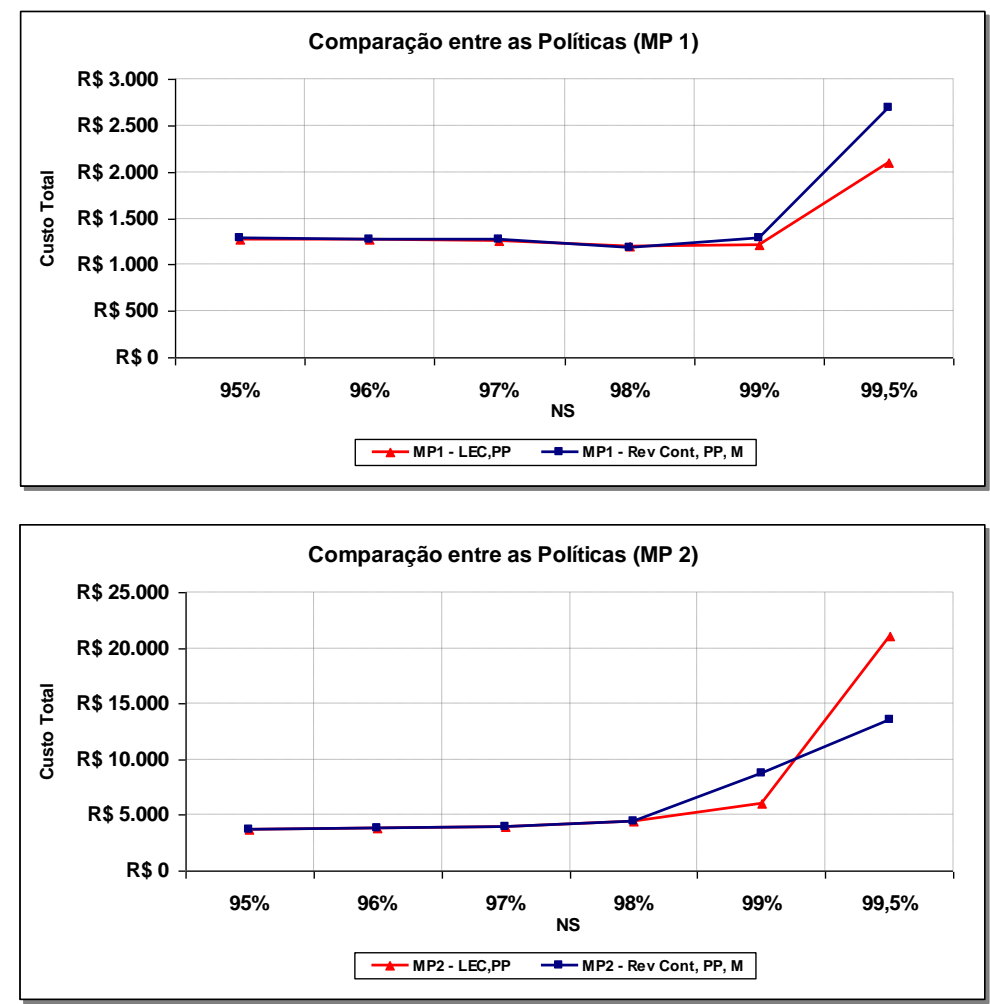

Fonte: Os autores (2008)

A Tabela 8 resume os valores de custo total compilados pelas simulações/sensibilidades, sendo que os valores grifados em cinza representam as maiores diferenças apresentas acima nos gráficos anteriores.

Tabela 8 - Resultados das Sensibilidades

\begin{tabular}{|l|c|c|c|c|c|c|}
\hline \multicolumn{1}{|c|}{ MP / POLÍTICA } & \multicolumn{5}{|c|}{ CUSTO TOTAL DAS POLITICAS POR NS } \\
\hline MP1 - LEC,PP & $95 \%$ & $96 \%$ & $97 \%$ & $98 \%$ & $99 \%$ & $99,50 \%$ \\
MP1 - Rev Cont, PP, M & $\mathrm{R} \$ 1.271$ & $\mathrm{R} \$ 1.269$ & $\mathrm{R} \$ 1.259$ & $\mathrm{R} \$ 1.195$ & $\mathrm{R} \$ 1.218$ & $\mathrm{R} \$ 2.094$ \\
MP2 - LEC,PP & $\mathrm{R} \$ 1.284$ & $\mathrm{R} \$ 1.277$ & $\mathrm{R} \$ 1.264$ & $\mathrm{R} \$ 1.177$ & $\mathrm{R} \$ 1.287$ & $\mathrm{R} \$ 2.686$ \\
MP2 - Rev Cont, PP, M & $\mathrm{R} \$ 3.683$ & $\mathrm{R} \$ 3.795$ & $\mathrm{R} \$ 3.984$ & $\mathrm{R} \$ 4.376$ & $\mathrm{R} \$ 6.053$ & $\mathrm{R} \$ 21.021$ \\
MP3 - LEC,PP & $\mathrm{R} 3.676$ & $\mathrm{R} \$ 3.767$ & $\mathrm{R} \$ 3.946$ & $\mathrm{R} \$ 4.386$ & $\mathrm{R} \$ 8.733$ & $\mathrm{R} \$ 13.552$ \\
MP3 - Rev Cont, PP, M & $\mathrm{R} \$ 13.473$ & $\mathrm{R} \$ 14.757$ & $\mathrm{R} \$ 16.770$ & $\mathrm{R} \$ 20.595$ & $\mathrm{R} \$ 35.594$ & $\mathrm{R} \$ 88.945$ \\
MP4 - LEC,PP & $\mathrm{R} \$ 6.562$ & $\mathrm{R} \$ 15.091$ & $\mathrm{R} \$ 17.015$ & $\mathrm{R} \$ 21.331$ & $\mathrm{R} \$ 36.341$ & $\mathrm{R} \$ 88.528$ \\
MP4 - Rev Cont, PP, M & $\mathrm{R} \$ 6.625$ & $\mathrm{R} \$ 7.040$ & $\mathrm{R} \$ 7.626$ & $\mathrm{R} \$ 10.782$ & $\mathrm{R} \$ 18.396$ & $\mathrm{R} \$ 44.347$ \\
\hline
\end{tabular}

Fonte: Os autores (2008)

\subsection{4 - Políticas de Revisão Periódica}

Um input necessário para simular estas políticas é calcular os intervalos de revisão a serem testados nas simulações, que podem ser vistos na tabela abaixo. Segundo Ballou (2006) uma 
aproximação razoável do intervalo ótimo de revisão pode ser dada pela divisão do Lote pela Demanda, o que pode ser visto na Tabela 9.

Tabela 9 - Intervalos de Revisão

\begin{tabular}{|c|ccc|}
\hline MATERIAL & DEMANDA MÉDIA & LEC & INTERVALO (R) \\
\hline MP 1 & 209 & 1.618 & 8 \\
MP 2 & 1.684 & 4.624 & 3 \\
MP 3 & 6.671 & 9.205 & 2 \\
MP 4 & 2.671 & 5.626 & 2 \\
\hline
\end{tabular}

Fonte: Os autores (2008)

\subsubsection{1 - Modelo de Revisão Periódica com Nível Fixo (M) e Intervalo Fixo entre}

\section{Pedidos (R)}

A Tabela 10 retrata um resumo dos indicadores das simulações desta política para as matérias primas.

Tabela 10 - Resultados do Modelo Rev. Per. Nível Fixo e Intervalo Fixo

\begin{tabular}{|c|c|c|c|c|}
\hline Indicadores & MP1 & MP2 & MP3 & MP4 \\
\hline Estoque Médio & 868 & 3.477 & 21.946 & 5.215 \\
\# Pedidos & 3 & 9 & 13 & 10 \\
Qtde Media Falta & 40 & 235 & 388 & 506 \\
Nivel de Servico & $78,3 \%$ & $80 \%$ & $94 \%$ & $78 \%$ \\
Custo Estoque & $\mathrm{R} \$ 575$ & $\mathrm{R} \$ 2.279$ & $\mathrm{R} \$ 14.386$ & $\mathrm{R} \$ 3.661$ \\
Custo Pedido & $\mathrm{R} \$ 270$ & $\mathrm{R} \$ 714$ & $\mathrm{R} \$ 1.025$ & $\mathrm{R} \$ 772$ \\
Custo Total & $\mathrm{R} \$ 846$ & $\mathrm{R} \$ 2.994$ & $\mathrm{R} \$ 15.411$ & $\mathrm{R} \$ 4.433$ \\
\hline
\end{tabular}

Fonte: Os autores (2008)

Apenas a MP 3 teve desempenho em serviço considerado razoável (em torno de 94\%), sendo as outra MPs tendo rendimento abaixo dos $80 \%$ de serviço.

\subsubsection{2 - Política de Revisão Periódica com Lote $(Q)$ e Intervalo Fixo entre Pedidos (R)}

A Tabela 11 permite visualização dos indicadores de desempenho na simulação desta política para as MPs. 
Tabela 11 - Resultados do Modelo Rev. Per. com lote Q e Intervalo Fixo

\begin{tabular}{|c|c|c|c|c|}
\hline Indicadores & MP1 & MP2 & MP3 & MP4 \\
\hline Estoque Médio & 752 & 1.562 & 6.364 & 1.919 \\
\# Pedidos & 6 & 11 & 25 & 14 \\
Qtde Media Falta & 19 & 610 & 1.595 & 1.044 \\
Nivel de Servico & $87,4 \%$ & $57 \%$ & $68 \%$ & $55 \%$ \\
Custo Estoque & $\mathrm{R} \$ 498$ & $\mathrm{R} \$ 1.024$ & $\mathrm{R} \$ 4.171$ & $\mathrm{R} \$ 1.347$ \\
Custo Pedido & $\mathrm{R} \$ 450$ & $\mathrm{R} \$ 864$ & $\mathrm{R} \$ 1.989$ & $\mathrm{R} \$ 1.133$ \\
Custo Total & $\mathrm{R} \$ 948$ & $\mathrm{R} \$ 1.888$ & $\mathrm{R} \$ 6.160$ & $\mathrm{R} \$ 2.480$ \\
\hline
\end{tabular}

Fonte: Os autores (2008)

Visualiza-se um desempenho razoável, em termos de serviço, apenas da MP 1 (87,4\%). Uma sensibilidade realizada para esta política foi tentar observar como se comportam os indicadores dados pequenos aumentos do tamanho do lote. A Figura 20, obtida na simulação (para a MP 1), mostra pequenos degraus de variação de custo de pedido com a variação do tamanho do lote, o que permite concluir que um determinado intervalo de tamanho de lote proporciona um número igual de pedidos com variações nos custos de estoque e no nível de serviço. Um posicionamento proposto nessa curva é o posicionamento na área dado um lote que proporcione um serviço adequado.

Figura 20 - Sensibilidade do Lote da MP 1 na Rev. Per. com lote Q e intervalo fixo (R)

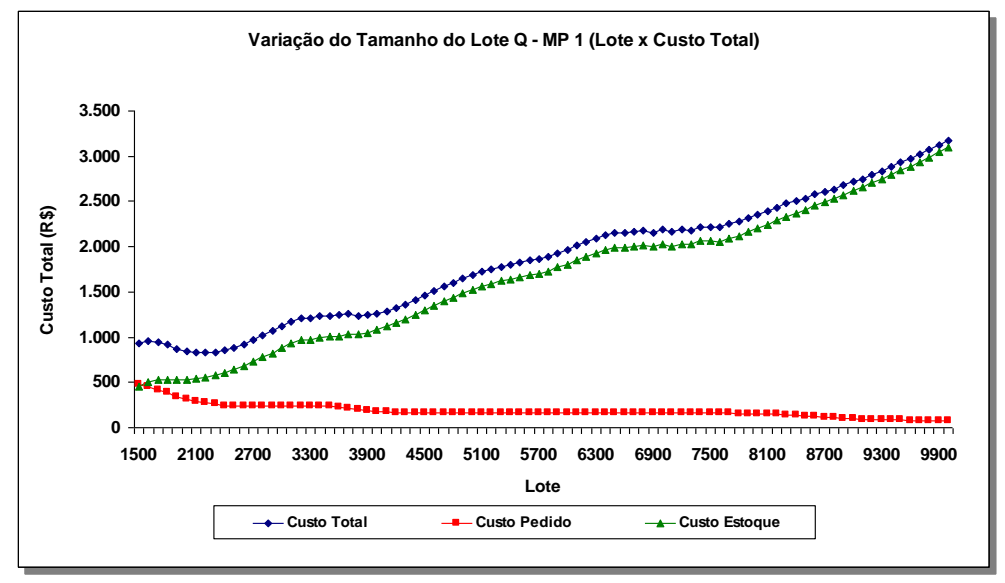

Fonte: Os autores (2008)

\subsubsection{3 - Comparação entre as políticas de revisão periódica}

A exceção da MP 1, as outras três, tiveram melhores resultados em serviço na política com teto $\mathrm{M}$, esse resultado pode ser entendido pelo fato que o pedido baseado em lotes fixos tem menor eficácia em reagir as variações de demanda que pedidos baseados na diferença entre o "nível" estipulado e o estoque existente. 
Fazendo conexão com o explicitado acima, a MP 1 teve um resultado de serviço bem superior as outra MPs no modelo com lote fixo, provavelmente devido a sua demanda mais estável, ocasionando uma menor quantidade de faltas entre os intervalos de revisão.

Um ponto que deve ser observado em políticas de revisão periódica é que estas proporcionam pedidos em conjunto podendo acarretar em descontos ou até mesmo em consolidação de cargas.

\subsection{Conclusões Finais do Estudo de Caso}

A Tabela 7, que mostra de uma maneira geral, redução dos níveis dos estoques, demonstra um desbalanceamento atual dos estoques, já que eram praticados níveis de estoques maiores e que provavelmente não desempenhavam um nível de serviço de $95 \%$.

Comparando as políticas de revisão contínua entre si, percebe-se certa similaridade no comportamento dos indicadores, havendo apenas algumas diferenças pontuais.

As políticas de revisão periódica não apresentaram desempenho muito satisfatório avaliando pelo indicador serviço, dado que as demandas possuem certo grau de variabilidade (médio e alto) que faz com que ocorram faltas entre os intervalos de revisão. Mas pode-se destacar que a política de nível fixo proporcionou de uma maneira geral resultados melhores que a política de lote fixo.

Um assunto não abordado neste estudo, mas que merece cuidado é o relacionamento com os fornecedores das matérias primas. As análises realizadas neste estudo podem não ter seus ganhos capturados caso não haja um bom relacionamento com os fornecedores.

Um bom exemplo pode ser visto quando se tenta traçar uma política com lotes mais enxutos de modo a se fazer mais pedidos com quantidades menores. Se o fornecedor se recusar a fornecer quantidades menores, devido à existência de lotes mínimos ou caso não consiga garantir o lead time acordado, a política poderá estar fadada ao fracasso.

Um comentário deve ser feito em relação à escolha das políticas, dado que nem sempre a melhor política (em termos de serviço e custo) acaba sendo a implementada. Em alguns casos modelos de revisão periódica podem não proporcionar bons resultados a princípio, mas a possibilidade de fazer pedidos em conjunto (característica da gestão com políticas desse tipo) pode reduzir custos de pedido e possibilitar consolidação de cargas, o que fazer com esse tipo de política em algumas situações se torne mais atrativa que outras. Outro ponto é que programar políticas de revisão contínua implica em se ter atualizado o nível de inventário de todos os itens, tarefa que nem sempre é executa com sucesso.

Por fim, as análises executadas vão proporcionar uma reflexão por parte da empresa de modo que outros estudos sejam executados e que possam segmentar os itens e propor políticas para cada grupo e que estas sejam implementadas nos sistemas de gestão e alimentem de maneira 
satisfatória a estrutura de produção das bebidas. E fica a mensagem que foram mostrados ganhos em custo e serviço com a simulação em algumas das políticas propostas.

\section{Conclusão}

A proposta inicial deste estudo foi avaliar o trade-off entre custo e serviço fazendo simulações com alguns modelos de estoques no ambiente do Microsoft Excel em conjunto com o @ Risk em uma empresa engarrafadora/distribuidora de bebidas que apresentava alguns problemas na sua gestão de matérias primas.

Para tal foi feita uma revisão bibliográfica onde se destaca inicialmente a definição de cadeia de suprimentos abordando que a mesma se consiste em todos os estágios envolvidos, diretos ou indiretamente, no preenchimento de uma ordem de um cliente, não incluindo somente fornecedores e fabricantes, mas também transportadores, atacadistas, varejistas e os próprios clientes.

Mais adiante se abordou o fato dos estoques terem relação direta com várias áreas das organizações e que elas têm necessidades diferentes e conflitantes tornando-se indispensável formalizar uma política para os estoques de modo a responder os principais questionamentos: quanto comprar, quando pedir o ressuprimento, dentre outros.

Aborda-se a função dos suprimentos na cadeia, que é bem sintetizada por BALLOU (2006) falando que sua função é satisfazer as necessidades dos sistemas de operações, tais como linhas de produção ou processos operacionais de um banco.

No capítulo seguinte são descritos alguns conceitos sobre simulação e suas aplicações e proposta uma metodologia de construção de modelos que será seguida no estudo de caso. Juntamente foram descritas características e funções da ferramenta @Risk que foi utilizada na elaboração do modelo de simulação.

Posterior a todas as revisões propostas partiu-se para o estudo de caso, onde inicialmente foi entendido o problema enfrentado e levantadas algumas informações necessárias para as posteriores análises.

Dentre os modelos de revisão contínua testados, destaca-se o com Ponto de Pedido e Nível Fixo (M), que proporcionou a realização de pedidos com diferentes tamanhos e dessa forma reagiu melhor às variações de demanda e consequentemente obteve-se melhores níveis de serviço.

Entre os modelos de revisão periódica, apesar de menos eficiente que os de revisão contínua, destaca-se o com Ponto de Pedido e Nível Fixo (M), que similarmente a explicação anterior apresentou melhor serviço dado o caráter variável do tamanho dos pedidos que proporcionou melhor reação as variações da demanda. 
Por fim, revisitando o conceito amplo de cadeias de suprimentos (BOWERSOX e CLOSS, 2001), se concluiu que independente da política selecionada pela empresa para implantação, a participação e colaboração dos agentes externos é de suma importância dado que os ganhos específicos em alguns elos podem não representar ganhos para a cadeia como um todo. Abordando os aspectos operacionais, uma política de estoque que, por exemplo, proponha um direcionamento para lotes menores com maior freqüência de ressuprimento depende da constância de entrega dos fornecedores, caso contrário, todos os ganhos desejados não serão capturados.

\begin{abstract}
The aim of this work is evaluate the impact of the different policies of raw materials inventory management using@risk as a simulation tool. As theoretical basis was made an analysis about value of stocks in the supply chain, showing the necessary decisions to elaborate an Inventory Policy, carrying out the description about supply logistic and its impact in a productive system and, finally, exploring aspects about simulation and the tool @ risk. The company analyzed is a bottler and distributor of drink, which confronts some problems in its raw materials inventory. The simulation shows, through key indicators, the several effects of different Inventory Policies and analyzes the several impacts in cost and service level to the raw materials studied, making possible the choose of the correct policy with the optimum total cost at the desired service level.
\end{abstract}

Key-words: simulation, inventory policies, bottler company.

\title{
Referências
}

AMARO, J. S. Custeio da cadeia logística: análise dos custos ligados ao comércio exterior. 2002. 132 f. Dissertação (Mestrado em Engenharia de Produção) - Programa de Pós-Graduação em Engenharia de Produção , Universidade Federal de Santa Catarina, Florianópolis.

BALLOU, R. H.. Logística empresarial. São Paulo: Atlas, 1993.

BALlOU, R. H.. Gerenciamento da Cadeia de Suprimentos/Logística Empresarial. São Paulo: Bookman, 2006.

BOWERSOX, D. J., CLOSS, D. J. Logística Empresarial: o processo de integração da cadeia de suprimento. São Paulo: Atlas, 2001.

CORREA, H. L.; GIANESI, I. G. N; CAON, M. Planejamento, Programação e Controle da Produção. 4. ed. São Paulo: Atlas, 2001.

FERREIRA FILHO, V. J. M. ; GARCIA, E. S. ; REIS, L. M. T. V. ; MACHADO, L. R. . Gestão de Estoques: Otimizando a Logística e a Cadeia de Suprimentos. Rio de Janeiro: e-papers, 2005.

FIUZA, C., Logística Integrada, Curso de Formação em Logística Empresarial, Notas de Aula, Rio de Janeiro, 2006.

FURTADO, P. G. ; CARVALHO, M. F. H. . Compartilhamento da informação como elemento de coordenação da produção em cadeia de suprimento. Gestão \& Produção, São Carlos, v. 12, n. 1, p. 39-53, 2005.

GAITHER, N.; FRAIZER, G. Administração da Produção e Operações. $8^{\circ}$ ed. São Paulo: Thomson, 2004.

Help da Versão do @Risk 4.5 para Excel produzido pela Palisade Corporation.

LAMBERT, D. M.; POHLEN, T. L. Supply chain metrics. The International Journal of Logistics Management, v. 12, n. 1, p. 1-19, 2001.

cross ${ }^{\text {ref }}$ 
LIMA, M.P. Estoque: Custo de Oportunidade e Impacto sobre os Indicadores Financeiros. Artigos CEL-COPPEAD, 2003. Disponível em: <http://www.centrodelogistica.com.br/new/fs-conheca.htm〉. Acesso em: 12 maio 2006.

MOORI, R. G.; BASSO, L. F. C.; NAKAMURA, W. T.. Supply chain como um fator de geração de valor: uma aplicação do conceito de EVA. Revista de Administração Mackenzie, São Paulo, n. 1, p.104-125, 2000.

PIDD, Michael. Computer Simulation in Management Science. $4^{\mathrm{a}}$ ed. Chichester: John Wiley \& Sons, 2003.

PRADO, C. A. da S.. Sincronização da produção: uma proposta de trajetória de implantação para a indústria têxtil. 2000. 214 f. Dissertação (Mestrado em Engenharia de Produção), Programa de Pós-Graduação em Engenharia de Produção, COPPE/UFRJ, Rio de Janeiro.

SALIBY, E.. Tecnologia de Informação: Uso da Simulação para Obtenção de Melhorias em Operações Logísticas. Artigos CEL-COPPEAD, 1999, Disponível em: <www.centrodelogistica.com.br〉. Acesso em: 01 maio 2006.

STERMAN, J. D. Business Dynamics: systems thinking and modeling for a complex world. Boston: McGraw-Hill, 2000 .

ZINSZER, P. Inventory models. Notas de aula SCM04. Disponível em http://whitman.syr.edu/facstaff/pzinszer/Spring2004/SCM401/chap005.ppt, Acessado em: 29 de jul. 2007.

WANKE, P., Aspectos Econômicos e Tecnológicos das Cadeias de Suprimento e Suas Implicações Gerenciais. Artigos CEL-COPPEAD, 2003. Disponível em: <http://www.centrodelogistica.com.br/new/fs-conheca.htm>. Acesso em: 12 maio 2006.

WANKE, P. Formalizando uma Política de Estoques para a Cadeia de Suprimento. In: FLEURY, P. F.; WANKE, P.; FIGUEIREDO, K. F. (Org.). Logística Empresarial: A Perspectiva Brasileira. São Paulo: Editora Atlas, 2000.

WANKE, P. Gestão de Estoques na Cadeia de Suprimentos: Decisões e Modelos Quantitativos. Rio de Janeiro: Editora Atlas S.a., 2003.

\section{Autores:}

Nome completo: Thiago Gomes da Silva

Filiação institucional: Centro Federal de Educação Tecnológica Celso S. da Fonseca.

Departamento: Engenharia de Produção

Endereço completo para correspondência (bairro, cidade, estado, país e CEP): Av. Maracanã, 229,

Maracanã, Rio de Janeiro, RJ, Brasil, 20271-110

Telefones para contato: (21) 25663022

e-mail: gomes.thiago@globo.com

Nome completo: Fabiano Barboza

Filiação institucional: Centro Federal de Educação Tecnológica Celso S. da Fonseca.

Departamento: Engenharia de Produção

Endereço completo para correspondência (bairro, cidade, estado, país e CEP): Av. Maracanã, 229,

Maracanã, Rio de Janeiro, RJ, Brasil, 20271-110

Telefones para contato: (21) 25663022

e-mail: fabianobarboza@gmail.com 
Nome completo: Lino G. Marujo

Filiação institucional: Centro Federal de Educação Tecnológica Celso S. da Fonseca.

Departamento: Engenharia de Produção

Função ou cargo ocupado: Professor Adjunto

Endereço completo para correspondência (bairro, cidade, estado, país e CEP): Av. Maracanã, 229, Maracanã, Rio de Janeiro, RJ, Brasil, 20271-110

Telefones para contato: (21) 25663022

e-mail: linomarujo@cefet-rj.br 